Tese apresentada ao Programa de Pós-Graduação em Biologia da Relação Patógeno-Hospedeiro do Instituto de Ciências Biomédicas da Universidade de São Paulo, para obtenção do título de Doutor em Ciências.

Área de Concentração: Biologia da Relação Patógeno-Hospedeiro

Orientador: Prof. Dr. Lincoln Suesdek

Versão corrigida. A versão original encontra-se disponível na Secretaria de Pós-graduação que aloja o Programa de Pós-Graduação.

\title{
São Paulo
}




\section{RESUMO}

Virginio-Fonseca, F. Morfometria geométrica e banco de dados na investigação de problemas biológicos em Culicidae. [Tese (Doutorado em Parasitologia)]. São Paulo: Instituto de Ciências Biomédicas, Universidade de São Paulo, Instituto de Ciências Biomédicas; 2018.

Enquanto muitas espécies de mosquitos são conhecidas por sua importância epidemiológica, a capacidade vetorial de algumas ainda não é clara. A identificação taxonômica, bem como a sexagem dos espécimes de Culicidae são essenciais para qualquer estudo ou ação, entretanto muitas vezes caracteres-chave estão danificados ou são restritos a uma fase de vida do animal. Em espécies crípticas, a identificação dos espécimes também pode ser prejudicada, o que dificulta, sobretudo, a compreensão da atividade vetorial em mosquitos. A morfometria geométrica alar, uma técnica barata e precisa para identificação de sutis dissimilaridades morfológicas, pode contribuir para a resolução destes tipos de problemas. O grupo de pesquisa MosquitoLab aplica esta técnica há mais de 10 anos e acumulou milhares imagens de asas com seus respectivos metadados. Estas informações, se organizadas como banco de dados relacional, podem permitir a sistematização do uso, consulta e armazenamento dos dados, além de viabilizar novos estudos e servir também como base para aplicações de identificação automática de mosquitos. Portanto, os objetivos deste trabalho foram avaliar a utilidade da morfometria geométrica alar para a resolução de dois problemas biológicos: dimorfismo sexual e espécies crípticas, e desenvolver um protótipo de plataforma para armazenamento de dados biológicos relacionados à morfometria de asa, por meio de um banco de dados relacional e um sistema web nomeado "WingBank". Com base na técnica de morfometria geométrica alar, dois estudos de caso foram realizados: a) avaliação do dimorfismo sexual de 10 espécies de mosquitos de interesse médico e, b) diferenciação morfológica alar de Anopheles strodei s.s. e Anopheles arthuri s.l. com base em dois diferentes conjuntos de pontos anatômicos. Para construção do protótipo do WingBank uma equipe multidisciplinar realizou levantamento de requisitos, modelagem e criação do banco de dados relacional, e implementação de uma plataforma web. Os resultados referentes ao dimorfismo sexual alar apresentaram significativa diferenciação entre os sexos e padrões específicos de forma alar em todas as espécies estudadas. Os pontos anatômicos alares mais variáveis foram os das regiões proximal e distal das veias mediana e radial. Fêmeas apresentaram asas significativamente mais largas e curtas do que os machos. Diferenciação morfológica alar entre as espécies crípticas avaliadas foi observada em ambos os conjuntos de dados (18 e 22 pontos), sendo que no conjunto de 22 pontos com alometria, foi mais evidente. Os pontos anatômicos mais variáveis nas análises com os conjuntos de 18 e 22 pontos foram 1,2 e 17, e 1, 2, 19, respectivamente. Finalmente, o protótipo WingBank foi implementado com dados referentes a 77 espécies pertencentes a 15 gêneros de Culicidae. Ao todo foram catalogados 13.287 registros de asas, dos quais 2.138 já estão disponibilizados a partir do presente trabalho, para uso de terceiros. Globalmente, este é o maior banco de dados de asas de Culicidae de que temos conhecimento.

Palavras-chave: Dimorfismo sexual. Subgrupo Strodei. Espécies crípticas. Identificação taxonômica. Morfometria geométrica alar. WingBank. 


\begin{abstract}
Virginio-Fonseca, F. Geometric morphometry and database in the investigation of biological problems in Culicidae. [Ph. D. Thesis (Parasitology)]. São Paulo: Instituto de Ciências Biomédicas, Universidade de São Paulo; 2018.

While many species of mosquitoes are known for their epidemiological importance, the vector capacity of some is still unclear. Taxonomic identification and sexing of Culicidae specimens are essential for any study or action; however, often key characters are damaged or restricted to a stage of life of the animal. In cryptic species, the identification of specimens can also be damaged, which makes it difficult to understand the vector activity in mosquitoes. Geometric morphometry, an cheap and precise technique for identifying subtle morphological dissimilarities, may contribute to the resolution of these types of problems. The MosquitoLab research group has applied this technique for more than 10 years and has accumulated thousands of wing images with their metadata. This information, if organized as a relational database, may allow the systematization of the use, consultation and storage of the data, besides making possible new studies and also serve as a basis for applications of automatic identification of mosquitoes. Therefore, the aims of this work were to evaluate the usefulness of the geometric morphometry to solve two biological problems: sexual dimorphism and cryptic species, and to develop a prototype of plataform for the storage of biological data related to wing morphometry, by means of a relational database and a web system named "WingBank". Based on the technique of wing geometric morphometry, two case studies were carried out: a) evaluation of the sexual dimorphism of 10 species of mosquitoes of medical importance and b) wing morphological differentiation of Anopheles strodei s.s. and Anopheles arthuri s.I. based on two different sets of landmarks. In order to build the WingBank prototype a multidisciplinary team performed requirements survey, modeling and creation of the relational database, and implemented a web platform. The results regarding wing sexual dimorphism showed significant differentiation between the sexes and specific patterns of wing shape in all species studied. The most variable landmarks were those of the proximal and distal regions of the medial and radial veins. Females showed slightly and significantly wider and shorter wings than males. Wing morphological differentiation between An. strodei s.s. and An. arthuri s.l. was observed in both sets of data (18 and 22 landmarks), but in the set of 22 with allometry, it was more evident. The most variable landmarks in the analyzes with the sets of 18 and 22 landmarks were 1,2 and 17, and 1,2, 19, respectively. Finally, the WingBank prototype was implemented with data referring to 77 species belonging to 15 genera of Culicidae. In all, 13,287 wing records were cataloged, of which 2,138 are from the present work, already available for use by third parties. Globally, as far as we know, this is the largest database of Culicidae wings.
\end{abstract}

Keywords: Sexual dimorphism. Strodei Subgroup. Cryptic species. Taxonomic identification. Wing geometric morphometrics. WingBank. 


\section{INTRODUÇÃO}

\subsection{A importância epidemiológica da família Culicidae}

As doenças cujos agentes etiológicos dispersam-se por vetores, como os mosquitos, são um dos maiores problemas de saúde pública mundial há séculos. Estas doenças, entre os séculos 17 e 20, causaram a morte de mais pessoas do que todas as outras causas combinadas [1], impediram o desenvolvimento de grandes áreas do trópico como a África [1, 2], foram temas de cartas trocadas entre Dom Pedro II e Pasteur [3, 4] e também prejudicaram obras como a construção do Canal do Panamá, a qual só pode ser concluída após medidas de controles [1, 2, 5].

A família Culicidae representa um importante grupo de insetos composto por diversas espécies vetoras de patógenos causadores de doenças. Dentre eles podemos citar vírus, filárias e plasmódios. Desde 1877, quando o papel dos mosquitos como vetores de filárias de humano para humano foi registrado por Patrick Mason, descobriu-se também, em anos seguintes, que malária, febre amarela e dengue tinham ciclos de transmissão similares [2]. A partir de então, uma sequência histórica foi registrada.

Apesar de, em 1854, Louis D. Beauperthuy [5] ter levantado pela primeira vez a hipótese de que a febre amarela poderia ser transmitida por mosquitos, e, em 1881, Carlos Juan Finlay [6] ter apresentado pela primeira vez em um congresso que o vetor do vírus da febre amarela era um mosquito, apenas em 1900, em Cuba, iniciou-se a primeira pesquisa oficial coordenada por Walter Reed [7], a qual testou esta hipótese. No Brasil, mesmo após as comprovações feitas pelos demais pesquisadores estrangeiros, havia resistência quanto ao meio de transmissão da febre amarela. Devido a isso, em 1902 Emílio Ribas e Adolfo Lutz decidiram realizar experimentos complementares no país [8]. Praticamente em paralelo aos acontecimentos relacionados à febre amarela, iniciavam-se os estudos sobre outra doença de similar importância para o Brasil e o mundo, a malária. Em 1897, Ronald Ross confirmou a hipótese de Laveran e Manson de que os mosquitos tinham relação com a transmissão da malária $[9,10]$.

Apenas a partir de 1900, a efetividade dos controles vetoriais começa a surgir, primeiramente em Cuba com o controle da febre amarela, seguido por Panamá, o qual erradicou a febre amarela e malária. O Brasil conseguiu a erradicação de 
Aedes (Stegomyia) aegypti Linnaeus, 1762. em 1955, referendada oficialmente pela Organização Pan-Americana da Saúde em 1958. No entanto, este controle vetorial manteve-se apenas até 1970, quando esta mesma espécie foi reintroduzida no território brasileiro, onde se estabeleceu até os dias atuais [11]. Em 1938, o governo brasileiro conseguiu controlar a infestação e em seguida erradicar Anopheles (Cellia) gambiae s.l. Giles do Brasil, uma espécie invasora como Ae. aegypti e que estava envolvida com a transmissão de malária. Em 1954, o Brasil obteve sucesso no controle de malária (Figura 1), porém, em 1975, o problema voltou a preocupar [11], principalmente na região amazônica. Vale ressaltar que um estudo recente, demonstrou que entre 2007-2014, a região extra-amazônica apresentou um total de 6.092 casos [12], e que a taxa de mortalidade causada pela malária na região extraAmazônica é maior que na região Amazônica [13].

O Brasil possui alguns exemplos de doenças relacionadas a mosquitos que causam grandes problemas de saúde pública, como dengue, febre amarela, zika e chikungunya, além das diversas doenças negligenciadas e subnotificadas. No entanto, malária ainda chama muita atenção no Brasil e no mundo [13]: Em 2014, cerca de 207 milhões de casos e 438 mil mortes relacionadas a ela foram registrados no mundo e, no Brasil os casos chegaram a aproximadamente 145 mil. Esta doença é causada por cerca de seis espécies de Plasmódios [14] e transmitida por pelo menos 60 espécies de Anopheles [15]. Estes dados são sempre preocupantes, pois além de ser um problema à saúde das pessoas, estas doenças têm um alto custo econômico e clínico para a sociedade [16-18].

Estudos recentes têm sugerido que mudanças climáticas e aquecimento global têm efeito direto no tamanho populacional, densidade e distribuição de vetores [1921], e que vários fatores ambientais influenciam na distribuição, inclusive, de vírus negligenciados, como Oropouche, Mayaro, Saint Louis e Rocio, sendo que a temperatura é a determinante central em áreas de alto-risco [22]. O Brasil possui uma larga extensão de florestas e ecossistemas naturais, além de possuir grandes centros urbanos os quais concentram grande número de pessoas e mosquitos antropofílicos, como o Ae. aegypti. No entanto, ainda são poucos os estudos que envolvem fatores ambientais e estes tipos de doença. 


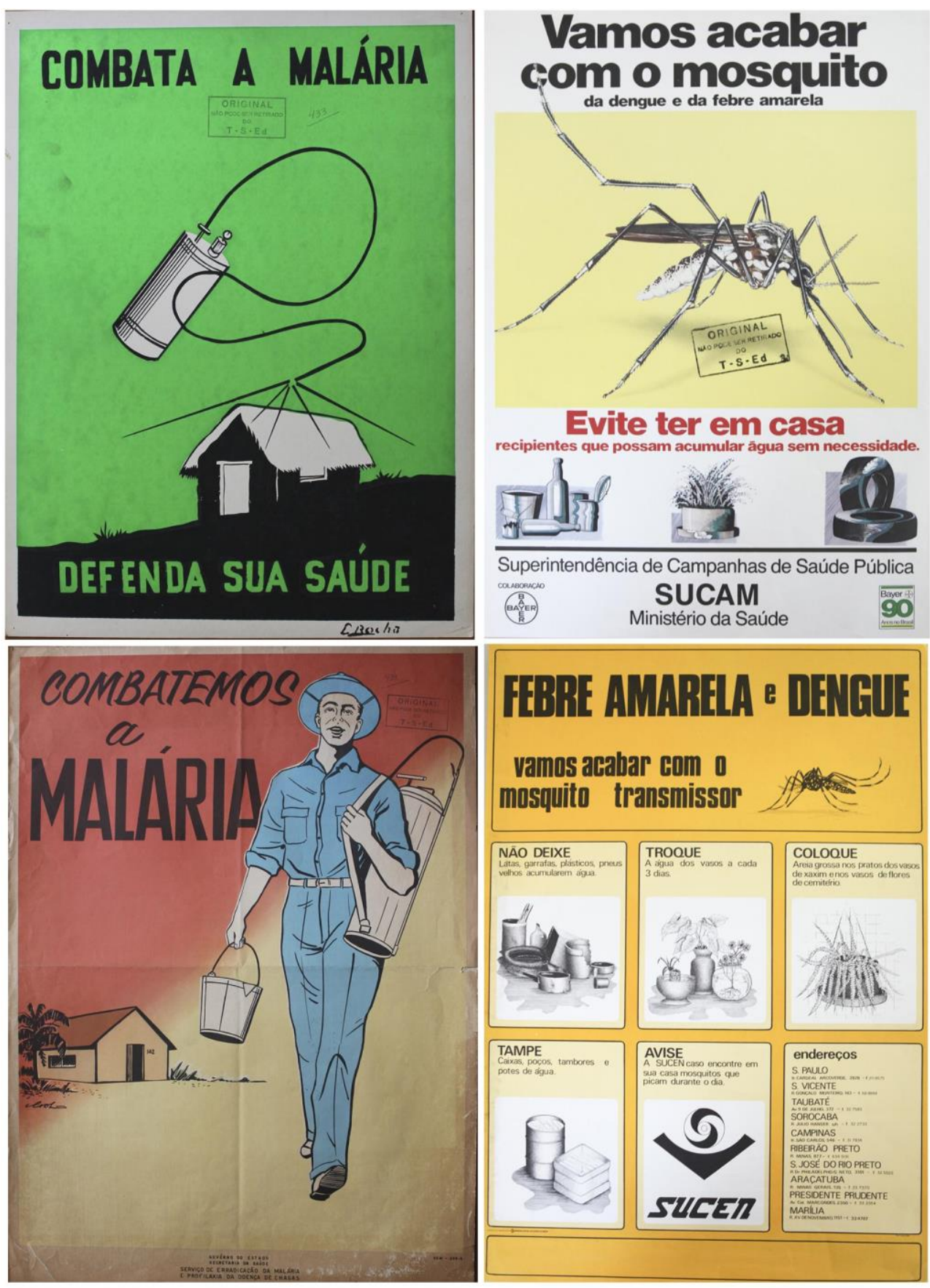

Figura 1 - Compilado de cartazes referente a campanhas de combate à malária (1950-1960) e febre amarela (1970-1990) no Brasil. Fonte: Coleção Cartazes de Campanha de Saúde. Acervo Museu de Saúde Pública Emílio Ribas / Instituto Butantan

O controle dessas doenças depende de muitos fatores, os quais o torna bastante complexo. A filariose linfática, desde a criação do Plano Nacional de Eliminação da filariose linfática no Brasil, em 1997, por recomendação do Conselho Nacional de Saúde, tem seus registros de casos diminuídos anos após anos [23]. A febre amarela urbana e dengue foram efetivamente controladas em grande parte 
das Américas do Sul e Central e eliminadas da América do Norte (exceto na Venezuela, ilhas das Antilhas e Sul dos Estados Unidos).

A malária já esteve perto de ser erradicada nas Américas. No entanto, durante as últimas décadas, devido a mudanças tanto nas políticas públicas em saúde quanto mudanças sociais e demográficas, mudanças na genética dos patógenos, além da resistência a inseticidas e medicamentos, diversas doenças relacionadas aos mosquitos têm emergido ou reemergido [11]. Além disso, ao longo do tempo, pode-se também perceber que fatores como a urbanização acelerada favoreceram o surgimento e a disseminação de novas, e a reemergência ou manutenção de antigas doenças infecto-parasitárias [24].

Apenas no ano de 2016, ocorreram surtos de pelo menos seis arboviroses pelo mundo: febre do Vale do Rift, febre amarela, oropouche, chikungunya, Zika e dengue [25], sendo que destes vírus, pelo menos cinco circulam atualmente no Brasil. Além disso, ocorreram reemergência de uma doença já conhecida pelos brasileiros, a febre amarela [26] e emergência de chikungunya e zika (263.598 e 211.770 casos prováveis em 2016, respectivamente) [27]. Devido à importância e influência que essas doenças possuem, é imprescindível estudá-las, incluindo o envolvimento das mais diversas espécies de mosquitos na dinâmica de suas transmissões [16].

Mais de 3.500 espécies de culicídeos já foram descritas no mundo [28], dentre as quais dezenas possuem relação comprovada na transmissão de agentes etiológicos ou apresentam alguma característica de interesse médico-veterinário [29], enquanto outras dezenas ainda necessitam de estudos referentes às suas capacidades e competências vetoriais.

Em 2007, o Brasil foi considerado o país com a maior riqueza de espécies de mosquitos (447 espécies), apresentando também um dos maiores números de espécies endêmicas [30]. Atualmente, no território brasileiro há cerca de 500 espécies (https://www.mosquitocatalog.org) de mosquitos tanto silvestres quanto urbanas. A família Culicidae é responsável por grande impacto à saúde pública no Brasil e em muitos países. Esta família alberga duas subfamílias, Anophelinae e Culicinae, sendo que a última congrega o maior número de representantes. Os gêneros Anopheles, Aedes e Culex estão entre os que possuem maior importância médica-veterinária [31]. 
Fêmeas da espécie Ae. aegypti atuam como vetores de diferentes agentes patogênicos aos seres humanos e outros vertebrados, dentre eles os vírus Dengue 1, 2, 3 e 4, Zika, Chikungunya e da Febre Amarela, além de também poderem transmitir microfilárias em áreas urbanas [32-34]. Mosquitos pertencentes a outras espécies do gênero Aedes, como Aedes (Stegomyia) albopictus Skuse, 1894 e Aedes (Georgecraigius) fluviatilis Lutz, 1904, são capazes de se infectar a nível laboratorial com o vírus da Febre Amarela [35-36] entre outros vírus [37-40], enquanto que um espécime de Aedes (Ochlerotatus) scapularis Rondani, 1848, já foi encontrado naturalmente infectado com o vírus da febre amarela [41]. No entanto, atualmente os vetores brasileiros do vírus da febre amarela que chamam atenção são os dos gêneros Haemagogus e Sabethes, considerando que apenas o ciclo silvestre está ocorrendo [42], o que não justifica a negligência da espécie Ae. aegypti perante a transmissão urbana desta doença. Mosquitos do gênero Culex podem transmitir microfilárias e vírus como o do Nilo Ocidental e o do Vale do Rift, participar da transmissão da encefalite japonesa [43-45] e, como recentemente descoberto, mosquitos da espécie Culex quinquefasciatus Say 1823 possivelmente também possuem competência vetorial para Zika [46].

Particularmente no Brasil, a malária pode ser dividida em malária amazônica e malária extra-amazônica (ou bromélia-malária). Estas subdivisões são baseadas principalmente na dinâmica de transmissão de cada área: na região amazônica em geral, os integrantes da espécie Anopheles (Nyssorhynchus) darlingi Root, 1926, são considerados vetores primários [48], salvo em alguns municípios como Macapá, onde a espécie Anopheles (Nyssorhynchus) marajoara Galvão e Damasceno assume esta posição epidemiológica [49, 50], enquanto que na extra-amazônica, o principal vetor é Anopheles (Kerteszia) cruzii Dyar e Knab [51-53]. Em algumas outras áreas específicas, An. darlingi e Anopheles (Nyssorhynchus) aquasalis Curry são incriminados como vetores de malária, como é o caso de Espírito Santo. Integrantes deste mesmo gênero também podem transmitir outros parasitas, geralmente em áreas rurais, como microfilárias [54-56].

No Brasil, principalmente devido à urbanização acompanhada pelo desmatamento, e também devido à reintrodução da espécie exótica Ae. aegypti, o país vem sendo marcado por diversas epidemias de doenças relacionadas a mosquitos. Esta espécie é uma das quais são amplamente conhecidas por sua importância primária na epidemia de diversas doenças, é uma das espécies 
invasoras mais bem-sucedida no mundo, além de atualmente ser uma das espécies mais relevantes no território brasileiro [57-58]. No entanto, esta não é a única que possui importância epidemiológica. Muitas outras desempenham ou podem desempenhar papel importante na dinâmica vetorial destas doenças (ver páginas 107 e 108), porém ainda são pouco ou nada estudadas.

É cada vez mais frequente o reconhecimento da importância de diversas outras espécies (até então negligenciadas) na transmissão de agentes etiológicos relacionados a estas doenças. Desse modo, destaca-se também a importância da investigação da capacidade e competência vetoriais em mosquitos potencialmente vetores, principalmente urbanos, os quais coexistem com a grande quantidade de humanos, o que favorece a rápida dispersão de uma epidemia.

Outro fator importante a ser considerado, o qual é impactante na obtenção do conhecimento sobre a capacidade e competência vetorial dos mosquitos, é a existência de complexos de espécies crípticas, as quais podem viver ou não em simpatria. Espécies próximas e/ou que fazem parte de complexos de espécies em Anopheles e que são vetoras de plasmódios, costumam ser encontradas em simpatria, como: Anopheles cruzii e Anopheles homunculus Komp no sudeste do Brasil [60, 61] e complexo Anopheles gambiae na África [62].

Além disso, as fêmeas possuem grande importância epidemiológica, pois são as únicas que se alimentam de sangue e podem então, transmitir patógenos aos animais. Enquanto que os machos desempenham outros papéis de importância equivalente, e são extremamente importantes para as estratégias de controle vetorial. Sendo assim, a sexagem correta dos mosquitos torna-se essencial para qualquer estudo.

\subsection{Importância da identificação de espécies crípticas na Família Culicidae}

O subgênero Nyssorhynchus é conhecido por abranger espécies de difícil identificação morfológica tanto entre fêmeas [63, 64], quanto entre machos [65]. Segundo Sallum [66], este subgênero é difícil de identificar utilizando apenas a morfologia, pois existem poucas diferenças nos caracteres externos. Assim, o esclarecimento morfológico desse grupo poderia, então, aumentar a eficiência no controle epidemiológico destes vetores. O Subgrupo Strodei de Anopheles (Nyssorhynchus) possui espécies crípticas ainda pouco estudadas [66-71], e essa 
falta de conhecimento pode dificultar a incriminação precisa dos vetores, como é o caso de An. Strodei, que já foi incriminado como vetor de malária [19, 72-74]. Porém, como é morfologicamente muito similar aos demais integrantes do Subgrupo Strodei, até o momento não se sabe qual espécie é realmente incriminada como vetor [69]. Este Subgrupo é amplamente distribuído desde o Panamá até o sul da Argentina. An. strodei s.l. demonstra alta zoofilia (porcos e gado), no entanto ainda pouco se sabe sobre o hábito alimentar destes animais [75]. Paralelamente, estudos taxonômicos e ecológicos [70], também estão sendo desenvolvidos, a fim de compreender melhor a dinâmica deste Subgrupo.

Este Subgrupo atualmente compreende as espécies: An. strodei, An. striatus, An. albertoi e An. arthuri, a qual possui indícios de que é subdividida em outras espécies (atualmente consideradas como An. arthuri A-D) [69]. Em 1926, baseado em caracteres morfológicos de fêmeas, machos, $4^{0}$ instar larval e pupa, de indivíduos coletados em Juiz de Fora - MG, Root descreveu Anopheles (Nyssorhynchus) strodei (Root, 1926). Em 1940, Unti descreveu a variedade ramosi Unti [76], com base em diferenças encontradas em 4ํinstar larval de indivíduos coletados em Lorena - SP. No ano seguinte, com base na morfologia de ovo, Unti [77] reconheceu as variedades albertoi, arthuri, artigasi, coletados em Rio ParaíbaSP, e a variedade Iloydi, coletada no Panamá. No entanto, em 1980, Faran decidiu sinonimizar todas as variedades descritas por Unti 1940 e 1941 com An. strodei. Porém, recentemente, Sallum et al. [66], com base em morfologia externa do ovo, genitália masculina e os genes white e COI, removeu An. strodei variedades albertoi e arthuri da sinonímia e reconheceu-as como espécie válida, além de reconhecer também a presença de uma nova espécie, hoje denominada An. striatus [71].

São cada vez mais frequentes os avanços no desenvolvimento de ferramentas moleculares para a discriminação de espécies crípticas e/ou irmãs com alta precisão [78], inclusive para espécies que vivem em simpatria, como é o caso de An. arthuri s.l. e An. strodei s.s., no entanto elas ainda tem custo elevado e requerem treinamento especializado [79]. A taxonomia tradicional, inclusive, consegue resolver alguns casos, no entanto também são vários os problemas envolvidos com esta técnica: está cada vez mais escassa a existência de especialistas na área de taxonomia, e no caso de An. arthuri s.I. e An. strodei s.s., por exemplo, além de a diferenciação morfológica ser bastante sutil (ver tabela comparativa em Sant'Ana e Sallum, [71]), a maioria das estruturas são específicas de machos (o que limita a 
identificação a 50\% das amostras) e de ovos (o que necessita da submissão das fêmeas coletadas à oviposição).

Em 2004, Fritz caracterizou An. strodei, Anopheles trinkae Faran, 1979, Anopheles rangeli Gabaldón, Cova Garcia e Lopez, e Anopheles triannulatus (Neiva e Pinto), utilizando sequências do Espaçador Interno Transcrito 2 (em inglês Internal Transcribed Spacer 2, ITS2) e descreveu um protocolo para identificação molecular [80].

Recentemente, Bourke et al. [69], por meio de análises filogenéticas utilizando ITS2 e os genes COI e white de amostras pertencentes ao Subgrupo Strodei, provenientes de diferentes localidades brasileiras, percebeu que quando concatenados os três genes (COI, white e ITS2) apresentaram-se sete clados monofiléticos bem suportados, o que sugere que, além das espécies já previstas, An. strodei, An. albertoi, An. arthuri e CP Form (An. striatus), existem outras três espécies, as quais os autores consideraram "tipos" do que hoje é chamado de $A n$. arthuri s.I. (nomeados, a priori como An. arthuri A-D) [69]. Aqueles mesmos autores perceberam que o gene ITS2 é suficiente para diferenciar An. strodei x An. albertoi $\mathrm{x}$ An. arthuri x CP Form (An. striatus) (Figura 2).

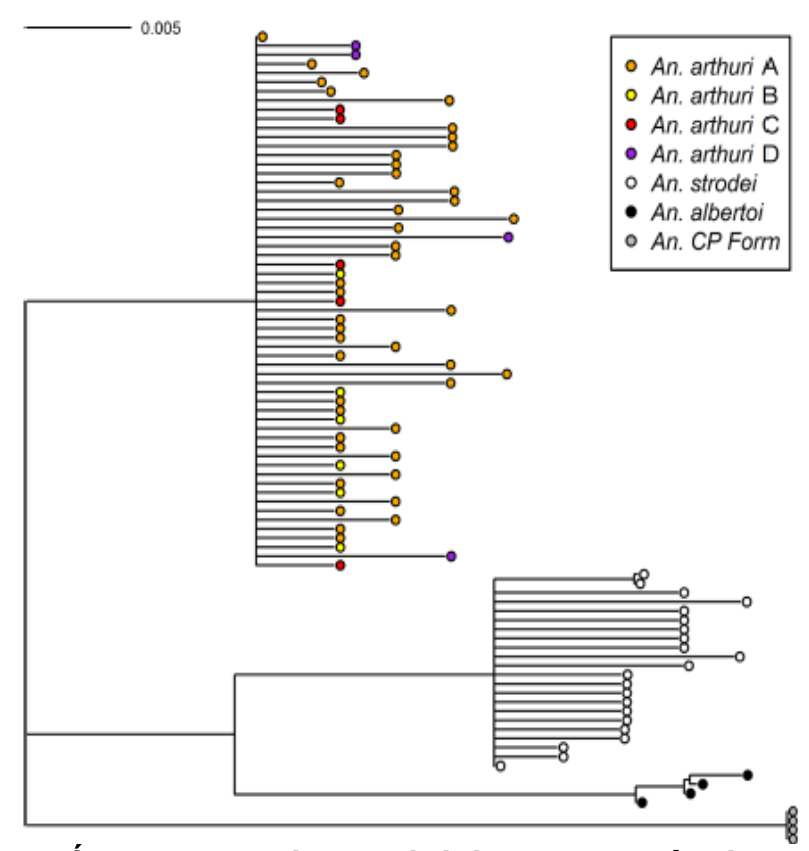

Figura 2 - Árvore de neighbor-joining de sequências de ITS2 do Subgrupo Strodei. Construída com distância Kimura-2Parâmetros, suportada por 10.000 bootstraps. Todos os clados tiveram suporte maior que 70\% (reproduzido de Bourke et al. [69]). 
Embora as múltiplas cópias de DNA ribossomal evoluam em concerto [81] e, devido a isso, apresentem baixa variação intraespecífica ou intragenômica, não é incomum encontrar alta variação em artrópodes vetores [82-85]. Entretanto ainda é vantajoso utilizar o ITS2 (localizado entre os genes 5,8 S e 28 S do DNA ribossomal) como marcador taxonômico molecular, pois: a) a sequência completa deste espaçador já é conhecida em muitas espécies do subgênero Nyssorhynchus; b) existe uma importante e considerável variação interespecífica, c) ele ocorre em múltiplas cópias, o que aumenta a sensibilidade de amplificação [80]. O espaçador ITS2 já foi utilizado individualmente e em conjunto com outros genes para identificação/distinção de espécies crípticas e/ou irmãs de mosquitos do gênero Anopheles [88-92]. Como este espaçador não codifica proteínas e evolui rapidamente, ele tem sido escolhido, inclusive, como marcador para estudos populacionais [93-95]. Comprimentos típicos do ITS2 variam entre 350-500 pb, entretanto já foram observadas variações de tamanho próximas a 600 e 700 pb em An. punctulatus e An. dirus, respectivamente [86, 87].

Um dos problemas críticos na taxonomia de Anopheles (Nyssorhynchus) spp. é reconhecer fêmeas de espécies-irmãs que vivem em simpatria [96]. Como uma alternativa, em Anopheles e outros gêneros, diversas espécies que podem ocorrer em simpatria têm sido estudadas por meio da técnica de MGA, como: $C x$. quinquefasciatus e Cx. nigripalpus [97], An. cruzii e An. homunculus [98], Cx. coronator e Cx. usquatus, An. nuneztovari e Anopheles rangeli [99], An. benarrochi B, An. oswaldoi s.l. e Anopheles strodei [100].

\subsection{A utilidade da morfometria geométrica como técnica e de asas como instrumento para a resolução de problemas biológicos}

Resultado da fusão entre geometria, biologia [101] e estatística [102], a MG permite o estudo multivariado da forma de estruturas biológicas em duas ou três dimensões espaciais. Esta técnica permite várias avaliações biométricas estatísticas e também a representação gráfica da forma e do tamanho, além de preservar a integridade física da forma e evitar o colapso em medidas lineares que não representam a estrutura como um todo [103]. Ela possui alto poder de resolução, uma vez que se baseia em análise de caracteres multivariados, o que permite a comparação simultânea de diferentes características em uma estrutura corporal 
complexa [102, 104]. Por meio desta técnica se pode comparar órgãos biológicos muito similares, pode-se evidenciar assimetria, dimorfismo sexual (DS), evolução morfológica, entre outras variações imperceptíveis ao olho humano, mas descritíveis pelas ferramentas geométricas e estatísticas.

A MG tem sido extensivamente utilizada para resolver diferentes problemas biológicos. Em alguns casos, possui grande utilidade quando aplicada isoladamente; em outros, sua combinação com técnicas de biologia molecular ou de taxonomia integrativa pode aumentar sua precisão [105].

Em mosquitos, a asa é a estrutura mais utilizada, principalmente devido à sua bidimensionalidade, o que aumenta a precisão e a repetibilidade mesmo quando são montadas e digitalizadas por diferentes operadores [106]. Em geral, a forma da asa é bastante informativa [107], sobre questões tanto hereditárias, quanto geográficas e evolutivas. Alguns estudos têm indicado que em dípteros, o formato da asa é herdável [108], tem determinação poligênica e é minimamente influenciado por fatores epigenéticos [109-110]. Embora relatos indiquem que o formato da asa sofre alguma influência por diferença de temperatura e fatores eco-geográficos [111,112], essa influência é mínima [105]. Portanto, a forma da asa se apresenta como um caráter mais estável do que o tamanho da asa, o qual é fortemente influenciado pelo meio (fatores climáticos e ambientais como: densidade larval em um mesmo criadouro, disponibilidade de comida, temperatura, etc.) [112, 113], e variações neste caráter devem ser interpretadas com cautela.

Os pontos anatômicos (PA), também conhecidos como landmarks, podem ser de três tipos: I) justaposição de tecidos; II) pontos de máxima curvatura ou outros processos (saliências) morfogenéticos locais; e III) pontos extremos [101]. Na maioria dos estudos de morfometria geométrica alar (MGA), utilizam-se os PA do tipo I, o qual inclui pontos no espaço onde três estruturas se encontram, como é o caso das interseções entre as veias alares dos mosquitos (Figura 3). A anotação destes pontos gera uma matriz de dados composta por suas coordenadas cruas em um plano cartesiano, essenciais para as análises subsequentes. Além destes tipos de anotações, pode-se também avaliar semi pontos (semi landmarks) e contornos das estruturas $[114,115]$. Uma das maiores vantagens da MG é a reconstituição gráfica da forma biológica original, o que é pouco viável com a morfometria tradicional. A partir destes dados, pode-se fazer diversas análises, como 
comparação da magnitude das variações e estudos estatísticos diversos [102, 116, $117]$.

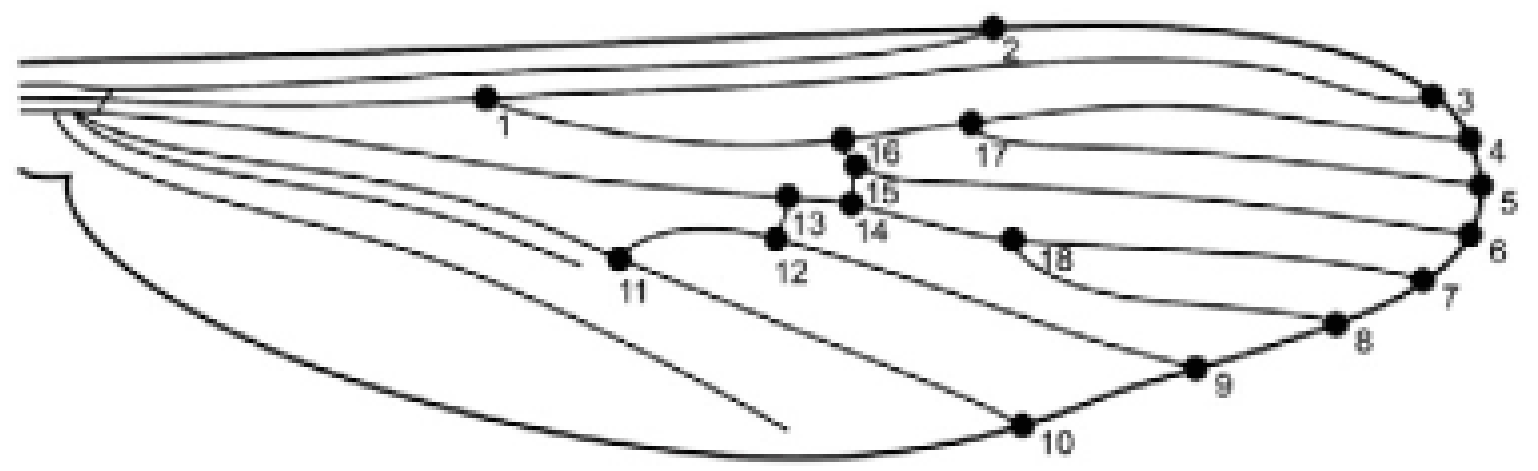

Figura 3 - Asa de mosquito do gênero Culex, com 18 pontos anatômicos anotados (reproduzido de Morais et al., [122]).

É importante também que os dados a serem utilizados nas análises sejam homólogos. Como existe uma sutil diferença anatômica entre as asas das subfamílias Culicinae e Anophelinae, caso haja interesse em compará-las, a tomada dos pontos deve ser padronizada como exemplificado na Figura 4. Ademais, Garros e Dujardin [79] sugerem que as resoluções (ou tamanhos) das imagens devem ser idênticas e, embora não exista uma regra, devem também ser a maior possível. Aqueles autores também aconselham que a escala de tamanho da imagem seja associada a cada imagem. Isso é importante, principalmente, para estudos relacionados ao tamanho isométrico das asas.

Particularmente em mosquitos, a quantidade de pontos anotados varia de 10 a 26, dependendo da escolha dos autores [105]. No entanto, a sequência de 18 pontos (Figuras 3 e 4), embora não seja um conjunto de dados universal, tem se mostrado suficiente para descrever DS [59, 118-121], variação intraespecífica [59, $110,113,119,122-126]$ e interespecífica, inclusive entre espécies-irmãs, crípticas e/ou pertencentes a complexo de espécies [97, 98, 127, 128]. 


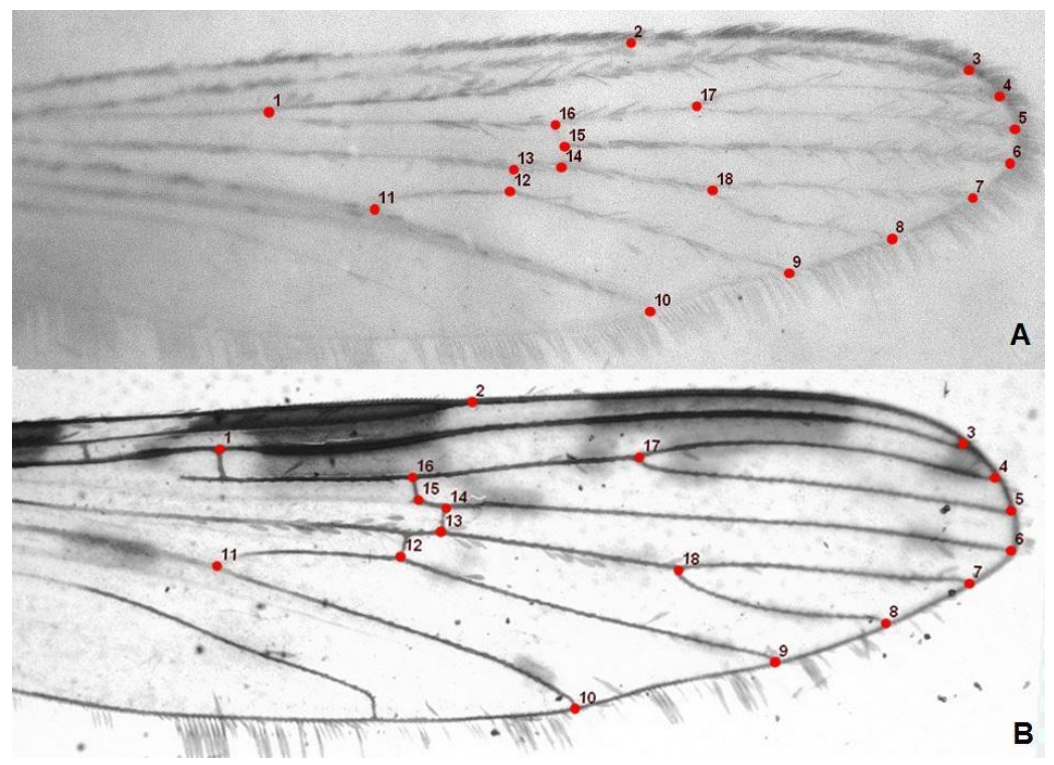

Figura 4 - A) Asa direita de fêmea de Culex nigripalpus; B) Asa esquerda de fêmea de Anopheles strodei s.s. Fotos: A) Paloma O. Vidal e B) Flávia Virginio

Em seu sentido estrito, a forma é a geometria de um objeto após a remoção da localização, orientação e tamanho [129]. Desse modo, quando objetiva-se analisar apenas a forma (sem descartar o efeito alométrico natural), a sobreposição de Procrustes (sP), uma das análises decorrentes da técnica de $M G$, elimina as variações artefatuais causadas justamente pela orientação, posição e pelo tamanho isométrico das asas [130]. As coordenadas residuais desta análise (também chamadas de partial warps) [131] são produzidas e seus componentes principais (também chamados de relative warps) podem ser comparados entre os grupos [132]. Já o tamanho da asa, de acordo com Dujardin [133], pode ser diretamente representado pelo tamanho do centroide (TC), o qual é formalmente representado pela raiz quadrada da soma das distâncias ao quadrado de todos os PAs até o centroide.

Caso o objetivo seja avaliar o tamanho e a forma alar isoladamente, a regressão multivariada da $\mathrm{SP} \times \mathrm{TC}$ deve ser adotada. Através desta análise, o efeito alométrico (efeito do tamanho isométrico sobre a forma) pode ser facilmente removido da análise, tornando possível a comparação entre as formas com mínima interferência dos diferentes tamanhos [134], além de possibilitar a avaliação do valor alométrico. 
Preliminarmente pode-se também obter informações sobre a existência de padrões por meio da representação gráfica do conjunto de dados multivariados a ser analisado, como por exemplo, a Análise de Componentes Principais (ACP) [102] a partir da qual se pode perceber a relação entre as características mais relevantes das amostras.

Outra análise importante na MG é a análise discriminante que utiliza Variáveis Canônicas. Esta análise permite avaliar quantitativamente a dissimilaridade entre amostras. Para tal usa-se, por exemplo, a distância de Mahalanobis (dM). Adicionalmente, existe outra distância importante para as análises de MG, a distância de Procrustes $(\mathrm{dP})$. Ambas as distâncias servem para estimar a dissimilaridade entre grupos num espaço multidimensional. A dM leva em consideração o quão incomuns são os indivíduos dentro de cada grupo, enquanto que a dP estima a distância entre os indivíduos de maneira mais generalizada e homogeneizada.

A assimetria é um fator importante o qual pode ser calculado por meio de ANOVA de Procrustes (Análise de Variância de Procrustes), a qual avalia as quantidades relativas de variação $[135,136]$ como, por exemplo, a diferenciação da asa direita em relação à asa esquerda.

\subsubsection{A morfometria geométrica alar em estudos de dimorfismo sexual em Culicidae}

Parte do conteúdo deste item está presente na publicação "Wing sexual dimorphism of pathogen-vector culicids" (DOI: http://doi.org/10.1186/s13071-0150769-6, Virginio et al. [120]).

Tipicamente, o DS é classificado dicotomicamente em dimorfismo sexual de tamanho (DST) e dimorfismo sexual de forma (DSF). Entretanto, sabe-se também que existe uma interação entre o tamanho e a forma do corpo, o que podemos chamar de DS alométrico. Contudo, embora em alguns casos o DS aparente ser resultado da alometria [137], exemplos de DS também podem ser atribuídos puramente ao tamanho [138] ou à forma [139].

Durante décadas, o DS em animais tem sido investigado sob pontos de vista evolutivos e ecológicos. Cerca de 140 anos atrás, Darwin [140] hipotetizou que o DS poderia ser um elemento da seleção sexual, ou seja, processo pelo qual a manutenção evolutiva de traços específicos do sexo poderia ser conduzida pela 
preferência do sexo oposto. Mesmo após quase um século e meio, a visão contemporânea sobre o DS, apesar de ter agregado novos dados empíricos, restrições e conceitos, ainda preserva a ideia subjacente por trás da hipótese de Darwin [141].

Insetos têm sido usados como modelos de estudos sobre DS para demonstrar que diferenças ligadas ao sexo podem ocorrer em vários órgãos, como olhos [142], pernas [143, 144] e cápsula cefálica [145]. Outras estruturas e características, como cerdas e antenas, tamanho do corpo, aparelhos bucais, genitália [146] e asas [118, $120,121,139]$ podem também ser observadas e utilizadas no processo de sexagem.

Em alguns grupos de insetos, o comportamento sexual, como som de cópula, pode depender da geometria das asas, as quais são específicas para cada sexo [107]. Estes podem ser indícios de que as asas dos insetos podem ter evoluído através da ação seletiva associada com o comportamento de cópula [147, 148].

Em Culicidae, sabe-se que apenas as fêmeas são hematófagas e competentes para a transmissão de patógenos, e que também utilizam suas asas para garantir uma precisa aproximação a outros animais e poder, então, sugar seu sangue; enquanto que os machos podem copular com várias fêmeas e utilizam a frequência do batimento de suas asas para compor um "dueto" com a fêmea durante a corte [149].

Apesar da importância epidemiológica dos mosquitos e da relação das asas com o comportamento destes insetos, poucos são os estudos sobre DSA em Culicidae. O DSA nesta família tem sido descrito ocasionalmente em chaves taxonômicas, mas seus padrões específicos e variabilidades ainda não são bem conhecidos. O dimorfismo sexual de tamanho e o dimorfismo sexual de forma alar (DSTA e DSFA, respectivamente) já foram reportados em pelo menos 11 espécies de mosquitos [118, 120,121], mas uma perspectiva comparativa entre espécies foi realizada apenas em um dos nossos estudos [120], do qual parte dos resultados será apresentada nesta tese.

Estudos sobre DSA em culicídeos podem indiretamente enriquecer nosso conhecimento acerca de sua epidemiologia dado que a relevância epidemiológica e o papel desempenhado pelas asas são particulares para cada sexo. O DSA deve ser estudado, pois pode estar atrelado a genes sexuais, os quais são especialmente úteis para o desenvolvimento de mosquitos geneticamente modificados, por exemplo $[150,151]$. Uma abordagem inicial para estudar o DSA em Culicidae pode ser 
detectar, quantificar e comparar o DSA em espécies as quais representam os principais subgrupos taxonômicos. Isso pode proporcionar informações preliminares sobre a frequência do DS e também sobre o papel das restrições filogenéticas e/ou adaptações específicas de cada espécie na evolução do DS.

\subsubsection{A morfometria geométrica alar no diagnóstico de espécies crípticas em Culicidae}

Embora a família Culicidae, comparada a outros grupos de insetos, possua uma sistemática relativamente organizada, ainda há discussões referentes ao status taxonômico de alguns gêneros e subgêneros [146, 152, 153]. Outro ponto importante na sistemática de Culicidae é a presença de complexos de espécies crípticas ou espécies-irmãs [154], principalmente no subgênero Nyssorhynchus de Anopheles. Espécies crípticas são duas ou mais espécies as quais, baseadas em suas similaridades morfológicas, são consideradas como apenas uma espécie, mas que, entretanto, estão em processo de reclassificação como espécies distintas com base em taxonomia integrativa, a qual envolve morfologia, filogenia e ecologia [155]. Espécies-irmãs, de acordo com Mayr [156], são populações morfologicamente similares ou idênticas, as quais são reprodutivamente isoladas, enquanto que complexos de espécies são espécies indistinguíveis morfologicamente, mas que podem apresentar diferenças no comportamento e variação genética [69].

Também são outros pontos a serem considerados: a diversidade de conceitos de espécie considerados para as segregações/identificações dos grupos (biológico, morfológico, filogenético, etc.) [157], além das particularidades para identificação destes grupos com base nos caracteres externos, pois somente alguns são considerados chave (genitália masculina, caracteres morfológicos dos ovos, caracteres presentes apenas na fase larval, etc.).

A identificação taxonômica precisa de alguns taxons em Culicidae pode ser bastante complexa. Considerando-se apenas a taxonomia tradicional, existe uma importante complexidade e subjetividade presente nas chaves dicotômicas, além da atual falta de profissionais especializados nesta área. Mesmo para um especialista em taxonomia de Culicidae, ainda existirá a extrema similaridade morfológica entre espécies muito próximas, o que muitas vezes só é resolvida a partir de taxonomia molecular, uma técnica ainda em constante desenvolvimento, que pode ser muito 
cara, mesmo que precisa. Somado a isso, ainda pode-se discutir sobre o tempo o qual é despendido para a aplicação destas técnicas, a má conservação de caracteres chave para a identificação, etc.

Devido ao alto poder de resolução da MG [104, 102], esta técnica tem se mostrado eficiente para, além de resolução de outros problemas biológicos, distinção de espécies-irmãs, simpátricas e/ou crípticas em Culicidae [97, 98, 127, 128]. Para isso, inclusive, diferentes conjuntos de PA já foram utilizados [99].

No entanto, ainda não é possível se obter uma identificação taxonômica exclusivamente por meio da MG, é necessário primeiramente haver a confirmação taxonômica por algum outro meio, para depois aplicá-la. Em alguns casos, a identificação prévia feita por meio da taxonomia tradicional pode ser suficiente, no entanto, em outros casos é necessária uma confirmação taxonômica molecular. Particularmente devido às dificuldades em caracterização dos membros do subgênero Nyssorhynchus (anteriormente mencionado), o marcador ITS2 é frequentemente escolhido.

Como supracitado, embora a MG seja útil para a distinção de grupos, ainda não está desenvolvida a identificação de espécies de mosquitos de maneira automatizada exclusivamente feita por MG. Funcionalidades de bioinformática poderão futuramente contribuir, por exemplo, como a criação de programas de digitalização e identificação automática de mosquitos, como visto para digitalização de asas de moscas [158] e identificação automática em abelhas [159]. A criação de BDs como o WingBank também poderá contribuir para novos avanços neste tipo de aplicação.

\subsection{A importância do uso de banco de dados e sua relação com morfometria geométrica alar de mosquitos}

Garros e Dujardin [79] enfatizam que para uso taxonômico, não basta apenas utilizar uma técnica poderosa como a MG, para avaliar as similaridades entre os taxons, é preciso também compartilhar os dados com outros pesquisadores, sejam eles genéticos ou morfológicos.

A ausência de bancos de dados de imagens alares tem dificultado testes de classificação ou identificação biométrica, bem como estudos de inferência biológica a longo prazo em insetos [160]. Ademais, em revisões temáticas sobre a MG de 
insetos de interesse médico, Dujardin [133] e Lorenz et al. [105] incentivam pesquisadores a utilizarem esta metodologia e enfatizam a importância de se construir bancos de dados morfométricos de Culicidae. Além disso, Garros e Dujardin [79] sugerem que para um Banco de Dados (BD) morfométricos ter utilidade taxonômica, ele deve compartilhar as coordenadas computadas ou as imagens.

A automatização da identificação de espécies baseado em MG além de demandar implementações computacionais, requer um BD que permita a validação desta aplicação por meio de testes. Atualmente, dois repositórios que compartilham imagens úteis para a MGA em insetos estão disponíveis, o ApiClass (http://apiclass.mnhn.fr) e o CLIC (http://mom-clic.com/clic-bank). O ApiClass é um sistema online especializado para identificação de subespécies de abelhas pertencentes à espécie Apis mellifera Linnaeus, 1758, com base nas asas, e que utiliza um Banco de Dados Relacional (BDR) (com 5.763 imagens) mantido com o Sistema de Gerenciamento de Banco de Dados (SGBD) MySQL. O CLIC é classificado pelo próprio autor como um "web space containing reference images" [161], ou seja, é uma base de dados mas não constitui propriamente um BDR. Entretanto, o WingBank (http://www.wingbank.butantan.gov.br), um BDR de informações morfológicas, por nós idealizado e desenvolvido por uma equipe multidisciplinar, surge com a proposta de ser o primeiro BDR com compartilhamento tanto das coordenadas computadas quanto das imagens, além de outros dados de interesse para taxonomia integrativa como dados espaço-temporais, exclusivamente de mosquitos.

\subsubsection{Importância local e global do WingBank}

O grupo de pesquisa MosquitoLab, o qual está sob a coordenação do Prof. Dr. Lincoln Suesdek, alocado no laboratório de Parasitologia do Instituto Butantan, nos últimos 10 anos produziu uma série de trabalhos relacionados à MGA de mosquitos, culminando recentemente com uma revisão científica [105]. Como matéria-prima para estes estudos, milhares de asas foram extraídas dos mosquitos, montadas, fotografadas e arquivadas em formato digital juntamente com uma série de informações morfométricas, e uma quantidade equivalente de informações 
biológicas/taxonômicas, geográficas/espaço-temporais, ambientais/climáticas e de recursos humanos foram anotadas em um livro-tombo.

A organização inicial destes dados se dava a partir do processamento tradicional de arquivos, onde cada usuário definia e utilizava os arquivos e suas respectivas informações vinculadas para um objetivo específico. Existia uma organização geral, mas no entanto, havia heterogeneidades organizacionais e particularidades vinculadas a cada projeto as quais refletiam nesta organização.

Inicialmente, o processo de armazenamento de dados no MosquitoLab seguia os passos descritos na Figura 5, onde: a) durante as coletas, cada coletor registrava os dados (geográficos, ambientais, etc.) de interesse específico para seu próprio estudo; b) o registro no livro-tombo se dava da seguinte maneira: criava-se um código da coleta o qual representava a combinação de diferentes caracteres: i) uma letra - cada livro tombo possuía uma letra que o representava ( $A$ ou $B$ ); ii) um numeral ou uma sequência numérica - cada página continha um número (001 a 200); iii) a letra T acompanhada por um numeral ou uma sequência numérica - cada linha de cada página do livro tombo era preenchida por informações mais específicas referentes ao "tipo" $(T)$ de coleta, de experimentação, espécie coletada e etc. Desse modo, obtinham-se códigos similares a "A1T2". O código de cada indivíduo não era registrado no livro tombo; c) as lâminas, em geral, contendo dois pares de asas (cada um referente a um indivíduo), cobertos por uma lamínula utilizando como solução de adesão bálsamo-do-Canadá, comumente eram identificadas com o código da coleta + número sequencial referente aos indivíduos + lado da asa + sexo do indivíduo; d) as asas eram fotografadas individualmente e o arquivo digital recebia o mesmo código anotado na lâmina/lamínula.

Assim, apesar de a organização dos dados suprir as necessidades do laboratório na época, existiam incompletudes de dados, visto que se o objetivo de um estudo específico não abrangesse certos tipos de dados, eles não eram anotados, ou se eram anotados, estavam em arquivos específicos de cada pesquisador e não no livro tombo. 


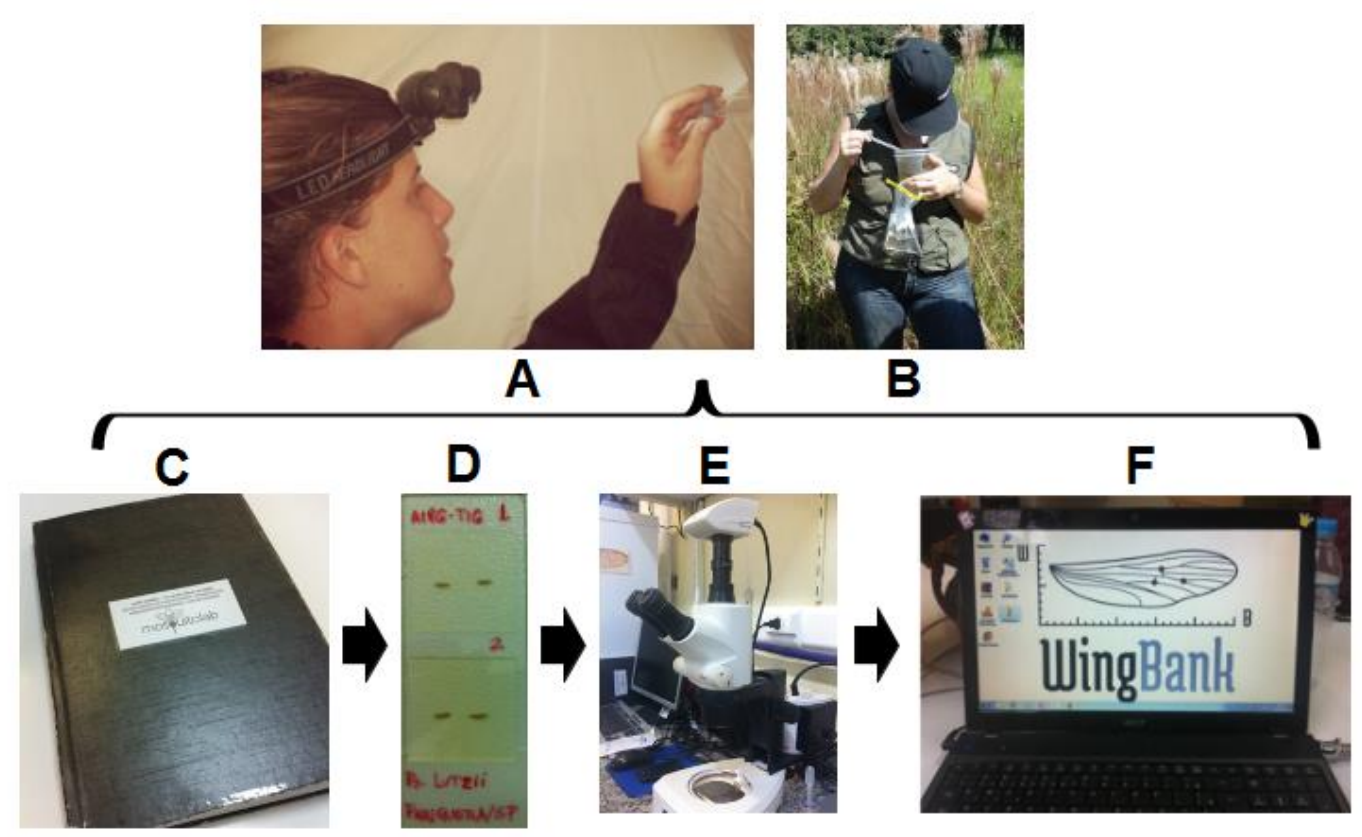

Figura 5 - Passos iniciais de registro de dados do MosquitoLab. A) e B) Coleta; C) Registro no livro tombo; D) Montagem das asas em lâminas; E e F) Registro fotográfico das asas.

Para garantir o referenciamento das imagens, as lâminas (Figura 6) foram triadas e depositadas no Laboratório Especial de Coleções Zoológicas (LECZ) do Instituto Butantan, onde cada asa recebeu uma etiqueta identificadora contendo um código sequencial de acordo com as políticas adotadas pelo LECZ e com as informações adicionais cedidas pelo MosquitoLab, como sexo, lado da asa e número do indivíduo (p.e. IBSP1.FD001).

Como uma tentativa de organização/padronização dos dados (quando ainda não se havia pensado em uma estrutura de BD), as informações registradas no livro tombo foram digitalizadas e as imagens, organizadas de acordo com cada registro. Inicialmente, os dados foram apenas tabulados em uma planilha eletrônica, em que cada linha representava o registro de um indivíduo e cada coluna representava um atributo do indivíduo, como data de coleta, sexo, etc. No entanto, a quantidade de dados cresceu ao longo dos anos, tornando inviável a busca por informação na planilha. 


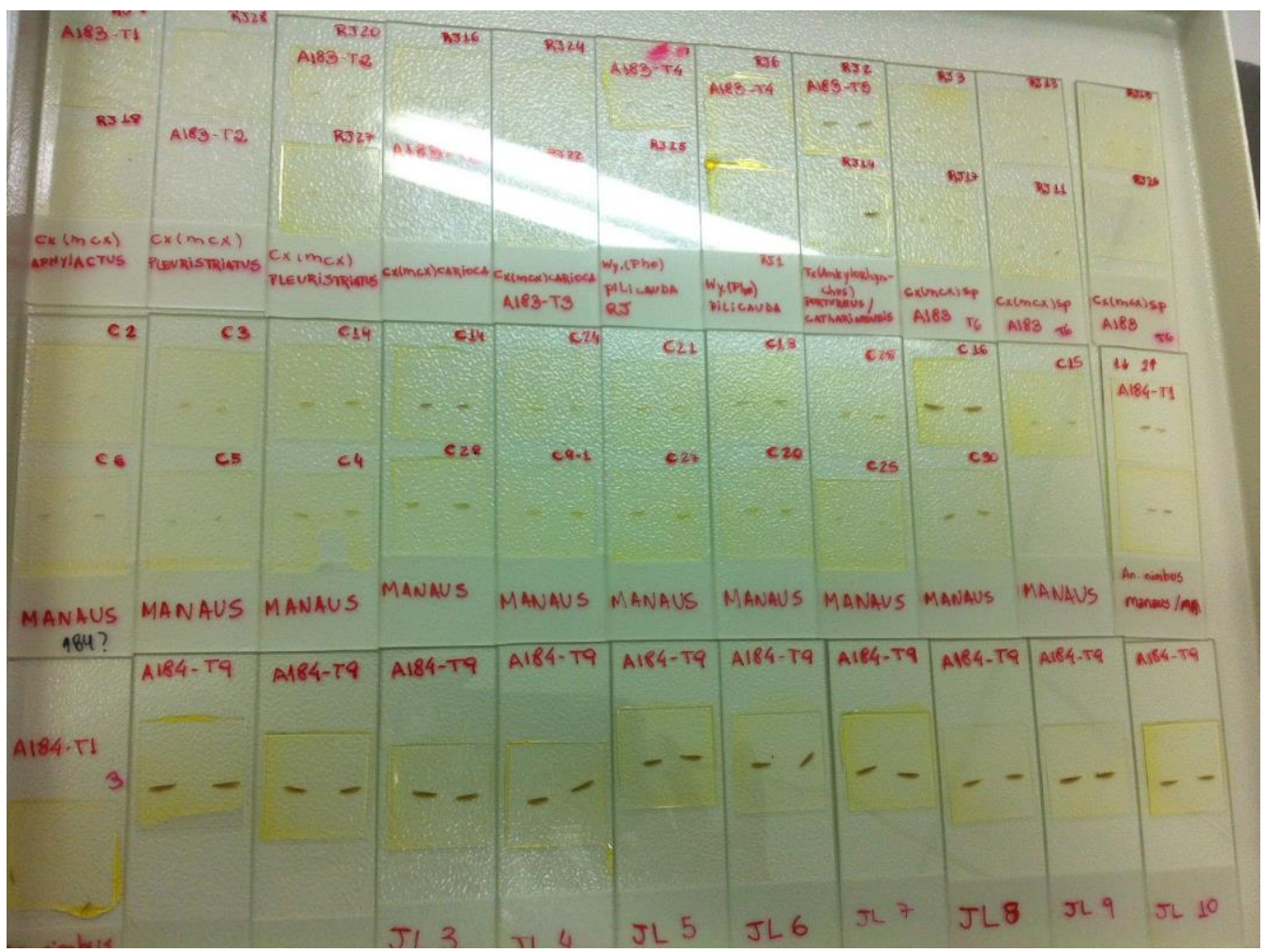

Figura 6 - Asas montadas entre lâmina e lamínula, identificação nãopadronizada.

Com a evolução das tecnologias de geração e armazenamento de dados ao longo das últimas décadas, tem se tornado cada vez mais comum o acúmulo de dados / documentos digitais, os quais precisam de uma organização específica para facilitar a sua recuperação. Um BDR, com o auxílio de um SGBD (explicações mais detalhadas na próxima seção, 1.5), possibilita a centralização do armazenamento destes dados [162].

Desse modo, ao invés de o usuário do MosquitoLab realizar pesquisa preliminar em dois locais distintos (livro tombo e computador), ele pode economizar tempo e recurso, buscando diretamente no WingBank. É esperado que o WingBank apresente para os usuários do MosquitoLab benefícios como os de organização de dados, facilitação de busca e acesso a todos os dados depositados (sem exceções). Atrelada a esta vantagem e com os ganhos adicionais, como possibilitar o armazenamento de informações de outras fontes no futuro, garantir integridade e consistência dos dados, evitar redundâncias e possibilitar a disponibilização pública destes dados, a implementação de um sistema de BD, composto por um BDR e um 
sistema web que provê uma interface amigável para o seu uso, pode ser uma interessante opção.

Além destes benefícios oferecidos ao público restrito (usuários MosquitoLab), considerando ainda como "importância local" o alcance nacional, estima-se que este banco seja importante para profissionais da área da saúde, como funcionários das vigilâncias entomo e epidemiológica, os quais poderão usufruir dos dados depositados vinculados a alguma publicação científica, para comparações e criação de novos estudos. No que concerne a "importância global", pretende-se que este banco seja acessado por usuários de qualquer parte do mundo (sejam eles estudantes de graduação/pós-graduação, pesquisadores científicos ou profissionais da área da saúde, e demais usuários extra-MosquitoLab), os quais poderão recuperar dados já vinculados a publicações científicas e utilizá-las para elaboração de novos estudos. Ademais, este banco, pode servir também como base para aplicações de identificação automática de mosquitos.

Vale ressaltar que a estrutura do WingBank poderá futuramente ser utilizada por outros grupos de pesquisa que queiram organizar seus próprios dados. Ademais, a padronização da nomenclatura dos arquivos de imagem das asas, p.e. 'F00000001L' (melhor detalhada no item 3.5.7) pode servir como base para outros grupos, principalmente os que utilizam o programa MorphoJ [180], devido à sua funcionalidade específica chamada "Extract New Classifier from ID String ...", a qual possibilita a classificação das amostras a serem analisadas com base no nome dos arquivos (input).

Com base nos dados apresentados pelo re3data (www.re3data.org), um registro global de repositórios de dados relacionados à pesquisa em diferentes disciplinas acadêmicas, existem cerca de 1000 bancos de dados registrados na área de Ciências da Vida, e 974 em Ciências Naturais. Estes números são bastante expressivos; juntos, correspondem a mais de sete vezes o número de registros da área com menos registros, que é a Engenharia (com 266) (Figura 7). Isso pode ser explicado pelo grande crescimento da produção de dados nos últimos anos, principalmente dos conhecidos como Big Data presentes principalmente na área de Biologia Molecular, reflexo da produção massiva de sequências gênicas [163]. Atualmente, o Brasil contribui com apenas seis registros no Re3data. 


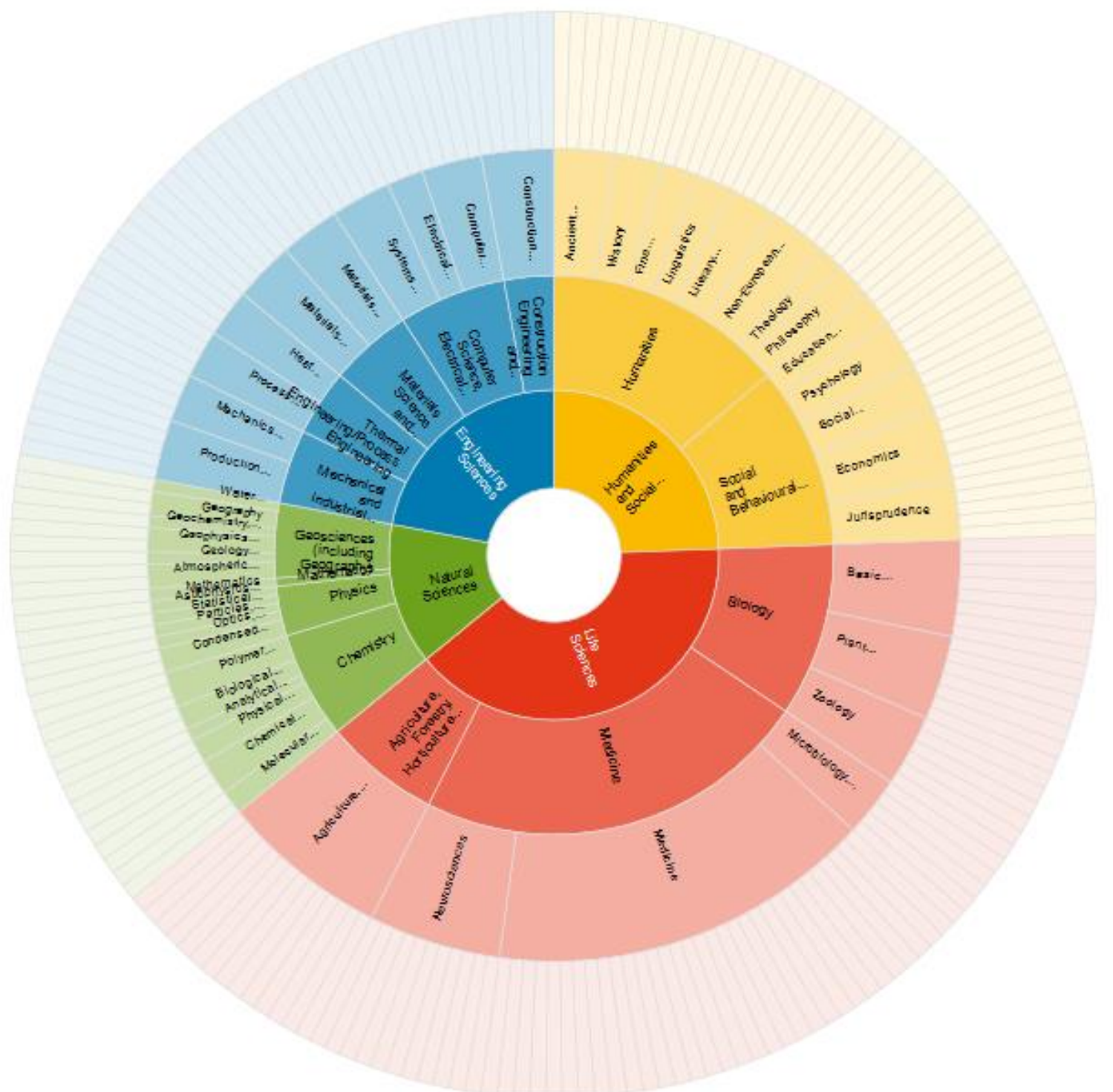

Figura 7 - Bancos de Dados registrados apresentados no re3data (www.re3data.org), separado por área.

$\mathrm{Na}$ Tabela 1, apresentamos uma amostra de bancos de dados relacionados com as áreas de Ciências da Vida e/ou Ciências Naturais, inclusive Entomologia Médica e MGA. Entre estes bancos de dados encontram-se, inclusive, alguns do tipo relacional, como: ApiClass, AnoBase e GigaDB. Vale ressaltar que nem todos os bancos de dados listados a seguir, estão registrados no re3data.org, o que significa que a quantidade de bancos de dados nestas áreas é ainda maior do que o indicado pelo Re3data. 
Tabela 1 - Exemplos de bancos de dados biológicos

\begin{tabular}{ccc}
\hline Nome & URL & Referência (DOI) \\
\hline $\begin{array}{c}\text { VectorMap (antigo } \\
\text { MosquitoMap) }\end{array}$ & http://vectormap.si.edu & $\begin{array}{c}\text { https://doi.org/10.1186/147 } \\
6-072 X-9-11\end{array}$ \\
\hline Mosquito Catalog & http://www.mosquitocatalog.org & ---- \\
\hline $\begin{array}{c}\text { Mosquito Taxonomic } \\
\text { Inventory }\end{array}$ & http://mosquito-taxonomic-inventory.info & --- \\
\hline $\begin{array}{c}\text { Zoobank - The Official } \\
\text { Registry of Zoological } \\
\text { Nomenclature }\end{array}$ & http://zoobank.org & --- \\
\hline Taxonomy Database* & https://www.ncbi.nlm.nih.gov/taxonomy & $10.1093 /$ nar/gkr1178 \\
\hline GigaDB* & http://gigadb.org & $10.1093 /$ database/bau018 \\
\hline Biofragment Database & http://vergil.chemistry.gatech.edu/active_b & http://dx.doi.org/10.1063/1. \\
fdb/bfdb/cgi-bin/bfdb.py & 5001028 \\
\hline FlyBase* & http://flybase.org & https://doi.org/10.1093/nar/ \\
gkw1016
\end{tabular}

*Bancos de dados registrados no re3data.org.

A história da Torre de Babel pode servir como metáfora para um problema existente na sistemática de insetos [164], mas também pode ser associada à extensa "produção independente" de programas e bancos de dados referentes às anotações gênicas [165], por exemplo. Para evitar a mesma incoerência na criação de bancos de dados de referência para MG, e apesar de o WingBank hoje ainda não se comunicar com bancos de dados de georreferenciamento (como o VectorMap), anotações gênicas (como o GenBank) e bibliográficos (como o PubMed), pretendese em um futuro próximo, conectá-lo a estes bancos de dados, bem como a outros bancos de dados que possam surgir.

\subsection{Conceitos básicos em Banco de Dados}

De uma maneira bastante simples, pode-se dizer que um BD é uma coleção de dados relacionados. Um BD digital pode ser convenientemente mantido por meio de 
um SGBD, uma coleção de programas que possibilita a criação e manutenção do BD [166].

Diversas vantagens decorrentes do uso de SGBDs são listadas por importantes estudiosos nesta área, como Date [167]: independência entre programas e dados, melhor desempenho nas operações de consulta e modificação dos dados, menos "trabalho duro" para a organização e manutenção dos dados, facilidade no compartilhamento e atualização de dados, controle de acesso, redução da redundância e prevenção de inconsistência, imposição de padrões e garantia de integridade. E Elmasri e Navathe [166], os quais fazem uma comparação entre as principais características da abordagem de processamento tradicional de arquivos e as da utilização de BD: no processamento tradicional, os arquivos de dados são criados e mantidos pelas próprias aplicações de programa que os utilizam, o que pode gerar redundância na definição e no armazenamento dos dados, levando ao desperdício de espaço de armazenamento e dificuldade na manutenção da consistência dos dados. Na abordagem baseada em BD, os dados são mantidos em um repositório único e ficam acessíveis a diferentes usuários e aplicações, além disso, os nomes (ou rótulos) dos dados são definidos uma única vez e utilizados repetidamente em consultas, transações e aplicações.

Ademais, os autores enfatizam a natureza auto-descritiva dos bancos de dados: um SGBD armazena os dados de um banco juntamente com informações sobre sua estrutura e as restrições que se aplicam a eles. Isso possibilita o isolamento entre programas e dados, ou seja, que edições nos programas não influenciem nos dados e vice-versa. No processamento tradicional, as estruturas dos arquivos de dados são embutidas nos programas de aplicação [166].

São características da abordagem baseada em BD: a abstração de dados, ou seja, destaque apenas para características essenciais para um entendimento dos dados; suporte para múltiplas visões dos dados; compartilhamento de dados e controle de acessos concorrentes, o qual possibilita a utilização (inserção e edição de dados, principalmente) de múltiplos usuários simultaneamente. As principais fases para a criação de um BD são: levantamento de requisitos, projeto conceitual, projeto lógico e projeto físico (Tabela 2) [166].

O tipo de BDR é o mais utilizado e considerado o de maior sucesso para a implementação de BD nas últimas três décadas, dominando o campo de gerenciamento de dados [168]. São alguns exemplos de BDR: aplicações científicas, 
as quais armazenam grandes quantidades de dados resultantes de experimentos científicos; armazenamento e recuperação de imagens; e aplicações de mineração de dados, as quais analisam uma grande quantidade de dados em busca de ocorrências de padrões específicos [166].

O modelo usado neste tipo de BD foi criado por Edgar F. Codd [169], e foi considerado uma ideia revolucionária na década de 70 [170]. A principal motivação foi uma observação feita sobre o fluxo de trabalho dos programadores da empresa IBM (International Business Machines) onde Codd trabalhava, os quais necessitavam reescrever grande quantidade de programas de aplicação manualmente sempre que o conteúdo ou organização física de um BD mudasse [168].

Este tipo de BD foi originalmente proposto para separar armazenamento físico dos dados das suas representações conceituais e fornecer fundamentos matemáticos para a representação e busca dos dados. Em um BDR, os dados são registrados como um conjunto de relações representados em tabelas, organizadas em tuplas (um conjunto de valores representados em linhas), sendo que cada tupla representa um registro. Uma tupla pode conter várias informações separadas, chamadas de atributos (campos). As tuplas de uma relação são identificadas univocamente por uma chave, que é um conjunto de atributos para os quais quaisquer par de tuplas da relação não podem ter valores iguais. Pode-se criar associações entre tuplas (possivelmente de diferentes relações), agilizando a busca de elementos que se relacionam entre si. Uma associação desse tipo é feita por meio de uma chave estrangeira, que consiste em um conjunto de atributos que apontam para a chave de outra tabela ou da mesma tabela, ou seja, o valor para uma chave estrangeira em um dado registro é o identificador unívoco de outro registro. A linguagem de consulta comumente utilizada neste tipo de BD é a Structured Query Language (SQL), um padrão da ANSI/ISO [166, 167].

\subsubsection{Criação de um Banco de Dados Relacional}

O projeto de um BDR inicia-se pelo levantamento de requisitos, que consiste basicamente na coleta de informações referentes aos interesses dos futuros usuários do $\mathrm{BD}$ e das aplicações de programa que com ele interagirão, a qual 
comumente é realizada com base em reuniões pontuais. Os requisitos são anotados com detalhamento, e com base neles, cria-se o modelo conceitual [166].

O modelo conceitual é conciso, descritivo e apresenta os principais requisitos do domínio modelado. Pode-se representá-lo de diferentes formas, a mais comum (e que foi usada no WingBank) é por meio de um Modelo Entidade-Relacionamento (MER) representado por um Diagrama Entidade-Relacionamento (DER), utilizando a notação gráfica, ambos criados por Peter Chen [171]. Um DER é estruturado em: a) entidades (retângulos), as quais representam a abstração de um objeto do mundo real no BD, como por exemplo, Indivíduo, Imagem e Identificação Taxonômica; b) atributos (elipses), os quais são detalhamentos, propriedades que caracterizam um tipo de entidade, como por exemplo, sexo do indivíduo, dimensão da imagem; e c) relacionamentos (losangos), os quais representam as associações entre as entidades, acompanhadas de suas restrições de participação e cardinalidades, como por exemplo: [Indivíduo] 1 <possui> 2 [imagem], [indivíduo] 1 <é> 1 [espécie], ou seja, cada indivíduo pode ter até 2 imagens, e cada indivíduo é correspondente apenas à uma espécie; os numerais representam a cardinalidade, como no exemplo hipotético apresentado na Figura 8. 


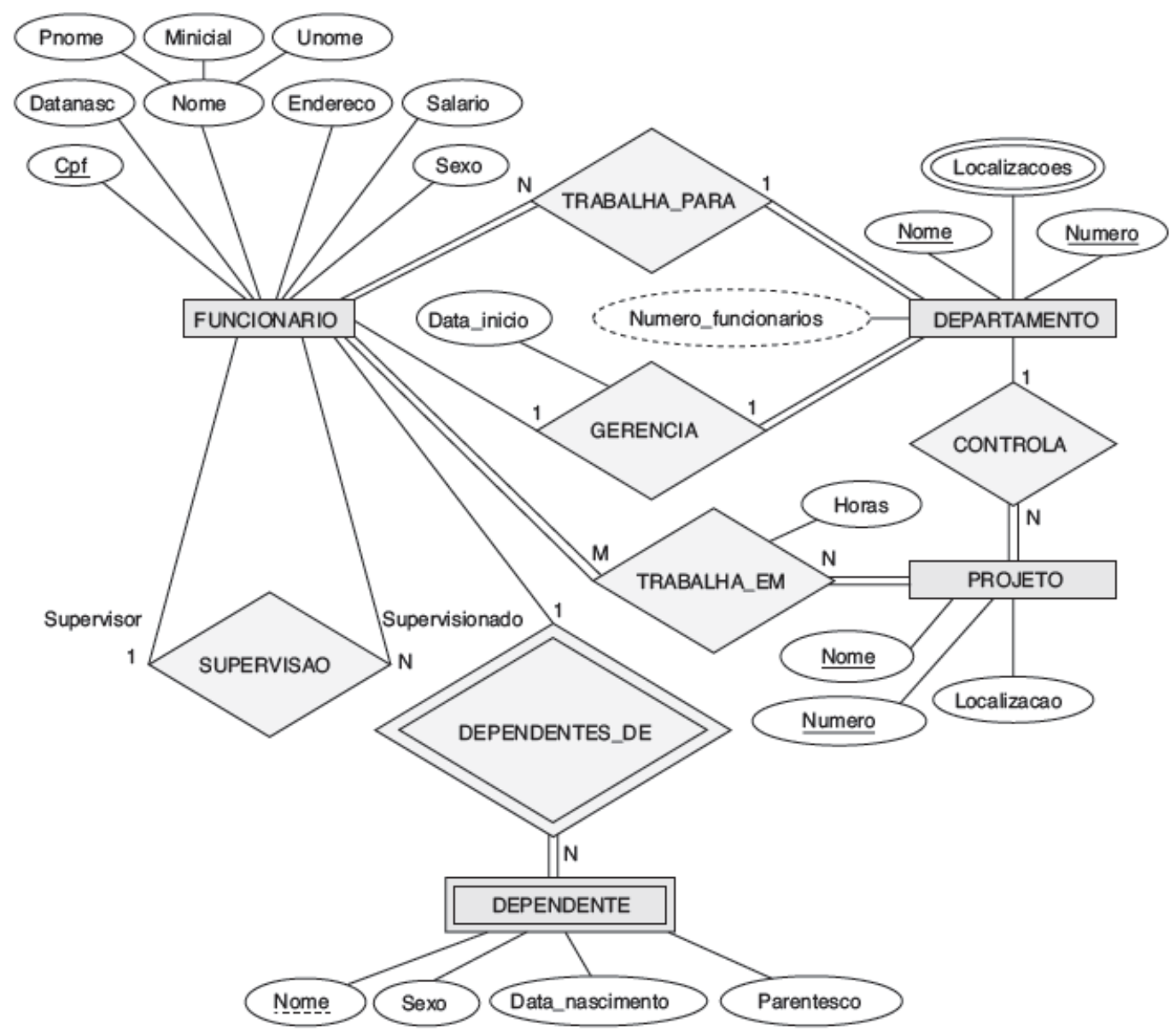

Figura 8 - Esquema DER para um banco de dados hipotético (reproduzido de Elmasri e Navathe, [166]).

As entidades são tipificadas em concretas (e definidas no diagrama por um contorno simples) ou abstratas (contorno duplo). Os atributos podem ser compostos (ou seja, subdivididos em mais de um atributo) ou simples; mono (com contorno simples) ou multivalorados (com contorno duplo). Os atributos chaves, ou seja, que identificam univocamente suas entidades, são denotados por um sublinhado sob o seu nome, enquanto que os que são chaves parciais são denotados por uma linha tracejada. Quando a participação de uma entidade em um relacionamento é parcial, a linha que liga a entidade ao relacionamento é simples; quando a participação é total, a linha é dupla [166].

Uma versão estendida do DER incorpora conceitos adicionais que permitem enriquecer a semântica do modelo conceitual. Esses conceitos são os de especialização/generalização e categoria (ou união). Uma especialização é a definição de subconjuntos de entidades (subclasses) de um tipo de entidade (neste caso, considerada uma superclasse), onde as subclasses possuirão atributos e/ou 
relacionamentos próprios e que, ao mesmo tempo, herdarão os atributos (inclusive, as chaves) da superclasse. Portanto, uma entidade de uma subclasse sempre é também uma entidade da sua superclasse. A generalização pode ser entendida como o processo inverso ao de especialização, em que se suprimem as diferenças entre vários tipos de entidades (subclasses), identifica-se suas características comuns $e$ as generaliza em uma única superclasse. Uma especialização/generalização pode ser do tipo sobreposta (denotada pelo símbolo "o" dentro de um círculo, do inglês "overlapping") ou disjunta (símbolo "d" dentro de um círculo, do inglês "disjunction"). Na disjunta, uma entidade da superclasse pode estar em no máximo uma das subclasses da especialização/generalização; na sobreposta, uma entidade da superclasse pode estar em várias subclasses. Uma categoria ou união (denotada pelo símbolo "u" dentro de um círculo, do inglês union) pode ser vista como um conjunto de entidades de diferentes tipos que não necessariamente possuem atributos em comum entre eles [166].

Em geral, o símbolo $\cap$ é adicionado ao relacionamento no qual se pretende representar a especialização/generalização ou categoria. A abertura deste símbolo é direcionada à entidade para a qual se está aplicando a restrição. Por exemplo, se a intenção é representar que um Indivíduo pode ter origem em uma coleta de campo, em uma colônia de laboratório, ou que ele pode ser coletado em campo, mas depois ser colonizado / mantido em laboratório, pode-se representar isso direcionando a abertura do símbolo à Origem (que é a superclasse de uma especialização sobreposta) como mostrado na Figura 9. Ademais, como a notação do MER nem sempre é suficiente para descrever todos os detalhes do BD, quando necessário, um dicionário de dados costuma ser elaborado para complementar o diagrama [166].

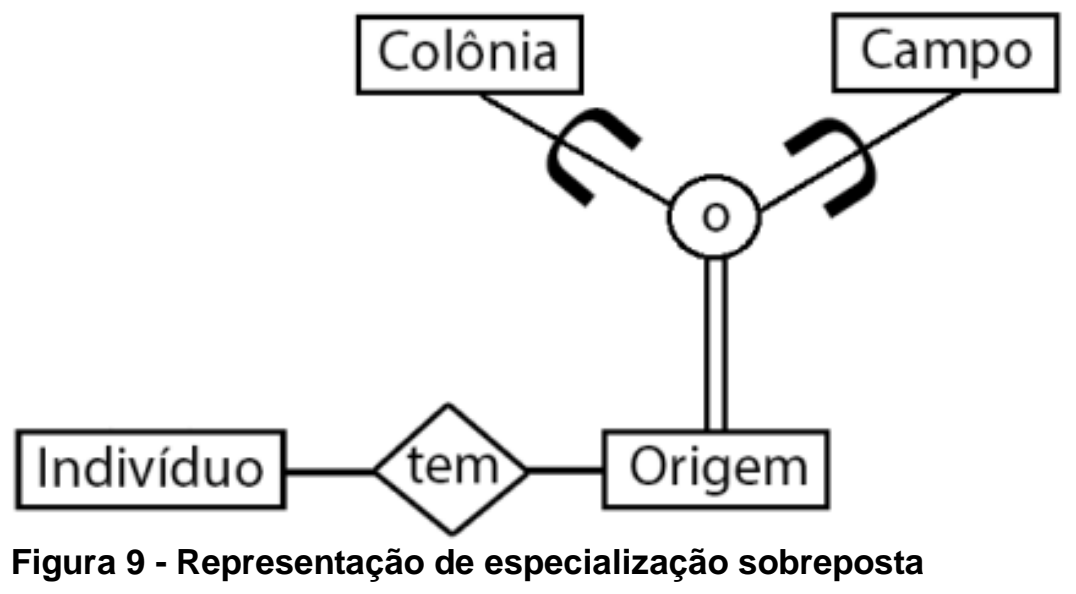


A modelagem lógica do BD corresponde ao mapeamento do esquema conceitual para um modelo de dados de implementação, que contém detalhes sobre os tipos de dados os quais compõem tal BD e as restrições que se aplicam sobre ele, por exemplo. No caso do WingBank, o modelo de dados de implementação escolhido foi o relacional, por razões já destacadas anteriormente neste texto. No mapeamento para o modelo relacional, os dados são apresentados "em tabelas, nada além de tabelas" [172], ou seja, os tipos de entidades são transformados em tabelas, os atributos em colunas das respectivas tabelas, os atributos multivalorados em outras tabelas, os relacionamentos em chaves estrangeiras e (possivelmente) novas tabelas. E então, para representar um esquema no modelo relacional, podese utilizar diferentes notações.

O programa usado para o desenho do esquema relacional do WingBank, o Visual Paradigm Community 14.1 (https://www.visual-paradigm.com), utiliza a notação "pé de galinha" criada por Everest [173], originalmente chamada de crow's foot (pé de corvo). Essa notação foi criada para a modelagem conceitual de dados, mas frequentemente é usada (combinada a outras notações) para representar graficamente restrições de cardinalidade e de participação sobre os relacionamentos expressos por meio de chaves estrangeiras em um esquema relacional. Um sumário da notação "pé de galinha" é apresentado na Tabela 3.

O refinamento do esquema é uma etapa opcional no projeto lógico, porém é comumente utilizado. Por meio dele é possível identificar problemas em potencial no esquema criado e aplicar técnicas para melhorá-lo.

Tabela 2 - Comparativo entre diferentes restrições de cardinalidade/participação e suas representações no diagrama relacional, de acordo com a notação "pé de galinha" de Everest [173].

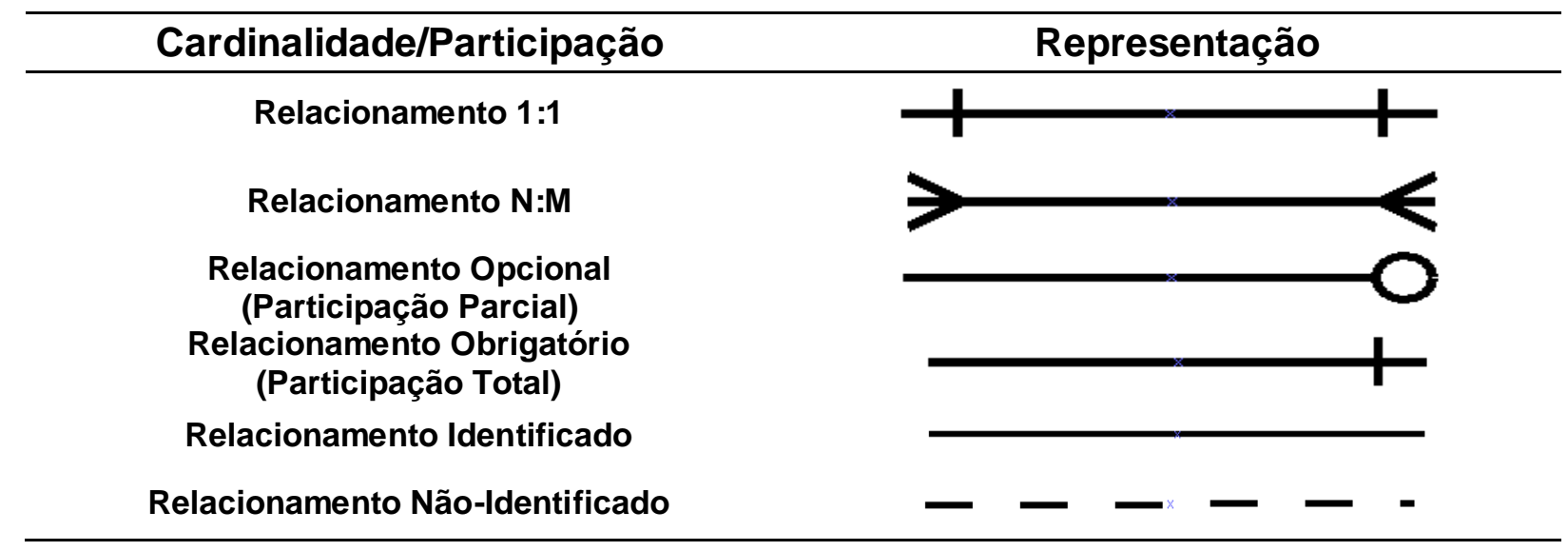


No modelo físico, algumas especificações finais são implantadas, principalmente as relacionadas a armazenamento e acesso ao BD. Nesta fase, alguns índices podem ser criados, tanto para garantir a coerência dos relacionamentos entre os dados, quanto para melhorar o desempenho das futuras operações sobre os dados [166].

Todas as operações realizadas sobre um BDR, desde a criação das tabelas até qualquer busca realizada pelo usuário final, podem ser realizadas por meio de uma linguagem de $\mathrm{BD}$, sendo que a Linguagem de Consulta Estruturada (Structured Query Language, SQL) é a melhor estabelecida até o momento. Apesar de a SQL ser única, ela é dividida em (pelo menos) três tipos: a) Linguagem de Definição de Dados (Data Definition Language, DDL), representada por comandos como CREATE, ALTER e DROP, os quais são criados para criar, alterar e deletar tabelas por inteiro, respectivamente; b) Linguagem de Manipulação de Dados (Data Manipulation Language, DML), são comandos como INSERT, UPDATE e DELETE, os quais interagem diretamente com os dados armazenados nas tabelas, ou seja, inserem, atualizam ou removem as informações dentro de uma tabela. c) Linguagem de Consulta de Dados (Data Query Language, DQL), a qual inclui o comando SELECT, usado para a recuperação de dados em um BD [166, 172, 174].

\subsubsection{Implementação de um sistema com acesso a Banco de Dados Relacional}

Há diferentes abordagens para o projeto e desenvolvimento de um sistema com acesso a BD. No WingBank, que é um sistema web, usou-se Projeto Orientado a Domínio (Domain-Drive Design, DDD) e Modelo-Visão-Controlador (MVC). O primeiro é uma abordagem de desenvolvimento que enfoca o entendimento das regras de negócio e de como elas devem estar refletidas no código do sistema e no modelo do domínio [175]. Além de esta técnica estar ligada às boas práticas da programação orientada a objetos, é uma forma de organizar o código de modo que as regras de negócios fiquem em contextos delimitados. Este projeto foi utilizado para a arquitetura de praticamente toda a aplicação, desde infraestrutura até o acesso aos dados. Para a comunicação entre a camada de modelo do sistema e o BD, usou-se o Mapeamento Objeto-Relacional (Object-Relational Mapper, ORM). O ORM é uma técnica que consiste em representar um objeto de programa de maneira relacional para que ele possa ser persistido (ou seja, gravado) em um BDR e, 
quando necessário, ser recuperado e criado como um objeto em memória principal novamente, sem que haja perda de informação nesse processo.

O segundo, o padrão MVC, foi utilizado apenas para a arquitetura da aplicação cliente da interface web. Neste padrão, a camada de modelo se refere à representação dos dados sobre os quais o sistema opera. A camada de visão é a apresentação dos dados e da lógica de processamento aos usuários finais, possibilitando inclusive sua interação com o sistema. Por fim, o controlador responde a eventos, gerencia o acesso ao modelo e à visão e coordena o fluxo de dados entre eles. 


\section{CONCLUSÕES}

\subsection{Principais Conclusões}

A morfometria geométrica alar se mostrou eficiente para a identificação de dimorfismo sexual alar em 10 espécies de mosquitos vetores de patógenos, bem como se mostrou eficiente para a diferenciação das duas espécies crípticas.

Foi observado tanto dimorfismo sexual de forma quanto de tamanho alar. No entanto, o dimorfismo sexual de tamanho alar se manifestou de modo diferente entre as espécies. A aparente canalização do dimorfismo sexual de forma alar em todas as espécies estudadas e a alta variabilidade de dimorfismo sexual de tamanho, parecem refletir complexos fatores evolutivos subjacentes;

Houve diferenciação morfológica de tamanho e forma alar significativa entre An. strodei s.s. e An. arthuri s.l. com base em ambos os conjuntos de pontos (18 e 22 pontos anatômicos), sendo que a anotação com 22 pontos anatômicos e com alometria se mostrou mais informativa;

O WingBank foi modelado e implementado, e já está disponíel (com acesso restrito) em https://www.WingBank.butantan.gov.br e em breve será oficialmente lançado pelo Instituto Butantan. Ele é o maior banco de dados de asas de Culicidae de que temos conhecimento, e o primeiro do tipo relacional e com as intenções propostas.

O WingBank é um banco de dados relacional o que o torna capaz de facilitar a busca por informações. Ele já possui 13.287 registros de asas, dos quais 12.939 já estão vinculados a imagens, e 2.138 imagens já estão disponíveis para utilização por terceiros, o que possibilita a realização de futuros estudos de meta- e reanálises. Cada registro ganhou um código de acesso, o que torna mais eficiente e confiável a citação a um registro de asas utilizadas em publicações. Por fim, estes mais de 13 mil registros já podem servir como base para futuros programas de identificação automática de mosquitos. 


\subsection{Conclusões adicionais}

a) Identificação de dimorfismo sexual:

Fêmeas das 10 espécies incluídas no estudo de dimorfismo sexual apresentaram asas ligeiramente mais largas e significativamente mais curtas do que os machos;

Os pontos anatômicos mais variáveis entre os sexos das 10 espécies analisadas quanto ao dimorfismo sexual alar foram os das regiões proximal e distal das veias medianas e radial;

Pode-se observar a ausência de dimorfismo sexual de tamanho alar em An. homunculus e uma inversão no padrão em An. cruzii s.l.. Além disso, An. cruzii s.l. também teve baixo dimorfismo sexual de forma, tornando esta espécie particularmente incomum comparada às outras analisadas neste estudo. Essa característica nestas duas espécies pode ser devido a fatores evolutivos e ambientais particulares a estas espécies, as quais são evolutiva e ecologicamente próximas;

A alometria aparentemente não direciona o dimorfismo sexual alar em Culicidae, apenas exerce uma influência marginal no dimorfismo sexual de forma. Desse modo, considerando que o dimorfismo sexual é prevalente e não primordialmente devido à alometria, acredita-se que complexos mecanismos evolutivos sejam responsáveis pela manutenção do dimorfismo sexual em mosquitos;

Possivelmente as espécies da subfamília Culicinae possuem diferentes padrões de dimorfismo sexual de forma alar, comparado à subfamília Anophelinae;

Caracteres morfológicos alares fornecem informações suficientes para estudos de dimorfismo sexual e são ferramentas práticas para identificar o sexo dos culicídeos. 
b) Diferenciação An. strodei s.s. e An. arthuri s.l.

De acordo com a comparação de similaridade entre as sequências de ITS2, observou-se que An. strodei s.s. e An. albertoi são mais similares, que An. strodei s.s. e An. arthuri s.l.. Isso corrobora os achados nos sítios diagnósticos (17/25 loci idênticos entre An. strodei s.s. e An. albertoi, contra 4/25 entre An. arthuri s.l. e An. albertoi);

O efeito alométrico, mesmo que baixo, foi significativo e influenciou a diferenciação entre An. arthuri s.l. e An. strodei s.s.;

Fêmeas de An. arthuri s.l. apresentaram asas isometricamente menores que An. strodei s.s. em ambos os conjuntos de dados (18 e 22 pontos anatômicos);

Não foi possível inferir com base nas informações genéticas e morfológicas obtidas no presente estudo, que os indivíduos pertencentes a An. arthuri s.l. avaliados são de algum dos subtipos ( $A, B, C$ ou $D)$;

c) Modelagem e Implementação do WingBank

O WingBank foi modelado, construído, implementado e está ativo, além de estar respondendo às buscas com desempenho satisfatório. 


\section{REFERÊNCIAS}

1. Gubler DJ. Insects In Disease Transmission. In: Strickland GT, Editor. Hunter Tropical Medicine, 7th Edition. Philadelphia (PA): W. B. Saunders. 1991;981-1000

2. Philip CB, Rozenboom LE. Medico-Veterinary Entomology: A Generation Of Progress. History Of Entomology. 1973. In: Smith RF, Mittler TE, Smith CN, Editors. History Of Entomology. Palo Alto (CA): Annual Reviews. 1973;333-359.

3. Calmon P. História De Dom Pedro II. Rio De Janeiro: J. Olympio. 1975;1-5.

4. Besouchet L. Pedro II E O Século XIX. Rio De Janeiro. 1993.

5. Beauperthuy LD. Fiebre Amarilla. Gaceta Oficial De Cumaná. 1854;57.

6. Finlay C. The Mosquito Hypothetically Considered As An Agent In The Transmission Of Yellow Fever Poison. Yale Journal Of Biology And Medicine. 1881.

7. Reed W. Propagation Of Yellow Fever; Observations Based On Recent Researches. 1901; 60:201-9.

8. Figueiredo LTM. A Febre Amarela Na Região De Ribeirão Preto Durante A Virada Do Século XIX: Importância Científica E Repercussões Econômicas. Revista Da Sociedade Brasileira De Medicina Tropical. 1996;29.

9. Ross R. Memoirs. With A Full Account Of The Great Malaria Problem And Its Solution. American Journal Of Public Health. 1923;13(11):959-60.

10. Rothstein WG. The Beast In The Mosquito: The Correspondence Of Ronald Ross And Patrick Manson. 1998.

11. Gubler DJ. Resurgent Vector-Borne Diseases As A Global Health Problem. Emerging Infectious Diseases. 1998;4(3):442-50.

12. Virginio F, Lorenz C, Aguiar BS, Suesdek L, Chiaravalloti-Neto F. Spatial And Temporal Epidemiology Of Malaria In Extra-Amazonian Regions Of Brazil. Malaria Journal. 2015;14(408).

De acordo com: International Committee of Medical Journal Editors. [Internet]. Uniform requirements for manuscripts submitted to biomedical journals. [2011 Jul 15]. Available from: http://www.nlm.nih.gov/bsd/uniform_requirements.htlm 
13. Pina-Costa A, Brasil P, Di Santi SM, Araujo MPD, Suárez-Mutis, MC, Santelli ACFES, Et Al. Malaria In Brazil: What Happens Outside The Amazonian Endemic Region. Memórias Instuto Oswaldo Cruz.109(5):618-33.

14. Calderaro A, Piccolo G, Gorrini C, Rossi S, Montecchini S, Dell'Anna ML, Et Al. Accurate Identification Of The Six Human Plasmodium spp. Causing Imported Malaria, Including Plasmodium ovale Wallikeri And Plasmodium knowlesi. Malaria Journal. 2013;12:321.

15. Bruce-Chwatt LJ. Essential Malariology. 2nd Ed. New York: John Wiley And Sons.; 1985;76,96,179-83.

16. Bôtto-Menezes C, Bardají A, Campos GDS, Fernandes S, Hanson K, Martínez-Espinosa FE, Et Al. Costs Associated With Malaria In Pregnancy In The Brazilian Amazon, A Low Endemic Area Where Plasmodium Vivax Predominates. Plos Neglected Tropical Diseases. 2016;10(3).

17. Shepard DS, Suaya JA, Halstead SB, Nathan MB, Gubler DJ, Mahoney RT, Et Al. Cost-Effectiveness Of A Pediatric Dengue Vaccine. Vaccine. 2004;22(9-10):127580.

18. Suaya JA, Shepard DS, Chang M-S, Caram M, Hoyer S, Socheat D, Et Al. Cost-Effectiveness Of Annual Targeted Larviciding Campaigns In Cambodia Against The Dengue Vector Aedes aegypti. Tropical Medicine And International Health. 2007;12(9):1026-36.

19. Laporta GZ, Linton Y-M, Wilkerson RC, Bergo ES, Nagaki SS, Sant'Ana DC, Et Al. Malaria Vectors In South America: Current And Future Scenarios. Parasites \& Vectors. 2015;8(426).

20. Sutherst RW. Global Change And Human Vulnerability To Vector Borne Diseases. Clinical Microbioly Reviews. 2004;17:136-73.

21. Githeko AK, Lindsay SW, Confalonieri UE, Patz JA. Climate Change And Vector-Borne Diseases: A Regional Analysis. Bulletin Of World Health Organization. 2000;78:1136-47.

22. Lorenz C, Azevedo T, Virginio F, Aguiar B, Chiaravalloti-Neto F, Suesdek L. Impact Of Environmental Factors On Neglected Emerging Arboviral Diseases. Plos Neglected Tropical Diseases. 2017.

23. Secretaria De Vigilância Em Saúde - Ministério Da Saúde Boletim Epidemiológico. 2016;47(9).

24. LUNA EJA. A Emergência Das Doenças Emergentes E As Doenças Infecciosas Emergentes E Reemergentes No Brasil. Revista Brasileira De Epidemiologia. 2002;5. 
25. World Health Organization. Disease Outbreak News - Emergencies Preparedness, Response 2016 [Disponível em: http://www.who.int/csr/don/archive/disease/vector-borne/en/].

26. Secretaria De Vigilância Em Saúde. Boletim Epidemiológico. Reemergência Da Febre Amarela Silvestre No Brasil, 2014/2015: Situação Epidemiológica E A Importância Da Vacinação Preventiva E Da Vigilância Intensificada No Período Sazonal. 2015.

27. Secretaria De Vigilância Em Saúde. Boletim Epidemiológico. Monitoramento Dos Casos De Dengue, Febre De Chikungunya E Febre Pelo Vírus Zika Até A Semana Epidemiológica 49. 2016.

28. Harbach R. Valid Species - Mosquito Taxonomic Inventory Updated 17 October 2017 [Disponível em: http://mosquito-taxonomic-inventory.info/valid-specieslist].

29. Munstermann LE, Conn JE. Systematics Of Mosquito Disease Vectors (Diptera, Culicidae): Impact Of Molecular Biology And Cladistic Analysis. Annual Review Of Entomology. 1997;42:351-69.

30. Foley DH, Rueda LM, Wilkerson RC. Insight Into Global Mosquito Biogeography From Country Species Records. Journal Of Medical Entomology. 2007;44(4):554-67.

31. Forattini OP. Culicidologia Médica: EDUSP; 2002. 860 P.

32. Cirio SM. Epidemiologia E Clínica De Cães Portadores De Dirofilariose Em Espaços Urbanos De Município Do Litoral Do Paraná E Aspectos Da Histologia De Culex quinquefasciatus (Say, 1823) (Diptera, Culicidae): Universidade Federal Do Paraná, Curitiba.; 2005.

33. Lee HL, Rohani, A. Transovarial Transmission Of Dengue Virus In Aedes aegypti And Aedes albopictus In Relation To Dengue Outbreak In An Urban Area In Malaysia. Dengue Bulletin. 2005;29:106-11.

34. Noridah O, Paranthaman V, Nayar S, Masliza M, Ranjit K, Norizah I, et al. Outbreak Of Chikungunya Due To Virus Of Central/East African Genotype In Malaysia. The Medical Journal Of Malaysia. 2007;62:323-8.

35. Amraoui F, Vazeille M, Failloux AB. French Aedes albopictus Are Able To Transmit Yellow Fever Virus. Eurosurveillance. 2016;21(39):15-7.

36. Davis N.C, Shannon RC. Studies On Yellow Fever In South America: Attempts To Transmit The Virus With Certain Aedine And Sabethine Mosquitoes And With Triatomas (Hemiptera). American Journal Of Tropical Medical Hygiene. 1931;11:219. 
37. Vanlandingham DL, Higgs S, Huang YJ. Aedes albopictus (Diptera: Culicidae) And Mosquito-Borne Viruses In The United States. Journal Of Medical Entomology. 2016;53:1024-8.

38. Wong PS, Li MZ, Chong CS, Ng LC, Tan CH. Aedes (Stegomyia) albopictus (Skuse): A Potential Vector Of Zika Virus In Singapore. Plos Neglected Tropical Diseases. 2013;7.

39. Gratz NG. Critical Review Of The Vector Status Of Aedes albopictus. Medical Veterinary Entomology. 2004;18:215-27.

40. Chompoosri J, Thavara U, Tawatsin A, Boonserm R, Phumee A, Sangkitporn $\mathrm{S}$, Et Al. Vertical Transmission Of Indian Ocean Lineage Of Chikungunya Virus In Aedes aegypti And Aedes albopictus Mosquitoes. Parasites \& Vectors. 2016;9:1.

41. Vasconcelos PFC, Costa ZG, Travassos Da Rosa ES, Luna E, Rodrigues SG, Barros VLRS, at Al. Epidemic Of Jungle Yellow Fever In Brazil, 2000: Implications Of Climatic Alterations In Disease Spread. Journal Of Medical Virology. 2001;65:598604.

42. Cavalcante KRLJ, Tauil PL. Risco De Reintrodução Da Febre Amarela Urbana No Brasil. 2017;26(3):617-20.

43. Lane, J. Neotropical Culicidae. University Of Sao Paulo; 1953.

44. Brustolin M, Talavera S., Nuñez A., Santamaría C., Rivas R., Pujol N., Valle M., Verdún M., Brun A., Pagès N, Busquets, N. Rift Valley Fever Virus And European Mosquitoes: Vector Competence Of Culex pipiens And Stegomyia albopicta (=Aedes albopictus). Medical Veterinary Entomology. 2017.

45. De SK, Chandra G. Studies On The Filariasis Vector - Culex quinquefasciatus At Kanchrapara, West-Bengal (India). Indian Journal Of Medical Research. 1994;99:255-8.

46. Guedes DRD, Paiva MHS, Donato MMA, Barbosa PP, Krokovsky L, Rocha SWD, et al. Zika Virus Replication In The Mosquito Culex quinquefasciatus In Brazil. Emerging Microbes \& Infections. 2017;6.

47. Mouchet J, Carnevale P, Coosemans M, Julvez J, Manguin S, RichardLenoble D, Et Al. Biodiversité Du Paludisme Dans Le Monde. John Libbey Eurotext. 2004:428p.

48. Tauil PL D-RC. Some Aspects Of Epidemiology And Control Of Malaria In Brazil. Revista Ibérica De Parasitologia. 1998;58:163-7.

49. Schiavi A. Nota Sobre Mosquitos Vetores Em Iguape. 1945. Arquivos De Higiene E Saúde Pública. 10: 69-75 
50. Conn J, Wilkerson R, Segura M, Souza R, Schlichting C, Wirtz R, et al. Emergence Of A New Malaria Vector Facilitated By Human Migration And Changes In Land Use. American Journal Of Tropical Medicine And Hygiene. 2002;66:18-22.

51. Forattini O. Entomologia Médica. São Paulo: Faculdade De Saúde Pública; 1962.

52. Aragão M. Sobre A Biomassa Dos Anopheles Do Subgênero Kerteszia Em Seus Criadouros. Memórias Do Instituto Oswaldo Cruz. 1968;66:227-37.

53. Deane L. Malaria Vectors In Brazil. Memórias Do Instituto Oswaldo Cruz. $1986 ; 81: 5-14$.

54. Buck A. Filariasis In: Strickland, T. G., Hunter's Tropical Medicine. 1991.

55. Mak JW. Epidemiology Of Lymphatic Filariasis. Ciba Foundation Symposium. 1987;127:5-14.

56. Manguin S, Bangs MJ, Pothikasikorn J, Chareonviriyaphap T. Review On Global Co-Transmission Of Human Plasmodium Species And Wuchereria bancrofti By Anopheles Mosquitoes. Infection, Genetics And Evolution. 2010;10(2):159-77.

57. Brown JE, Evans BR, Zheng W, Obas V, Barrera-Martinez L, Egizi A, et al. Human Impacts Have Shaped Historical And Recent Evolution In Aedes aegypti, The Dengue And Yellow Fever Mosquito. Evolution. 2014;68(2):514-25.

58. Gloria-Soria A, Ayala D, Bheecarry A, Calderon-Arguedas O, Chadee DD, Chiappero M, et al. Global Genetic Diversity Of Aedes aegypti. Molecular Ecology. 2016;25(21):5377-95.

59. Vidal PO, Carvalho E, Suesdek L. Temporal Variation Of Wing Geometry In Aedes albopictus. Memórias Do Instituto Oswaldo Cruz. 2012;107(8):1030-4.

60. Smith LB. Bromeliad Malaria. Annual Report Of The Board Of Regents Of The Smithsonian Institution. 1952;92:385-98.

61. Marrelli MT, Malafronte RS, Sallum MA, Natal D. Kerteszia Subgenus Of Anopheles Associated With The Brazilian Atlantic Rainforest: Current Knowledge And Future Challenges. Malaria Journal. 2007;6:127-35.

62. Levine RS, Peterson AT, Benedict MQ. Geographic And Ecologic Distributions Of The Anopheles gambiae Complex Predicted Using A Genetic Algorithm. American Journal Of Tropical Medicine And Hygiene. 2004;70:105-9.

63. Hribar L. Effect Of Larval Rearing Temperature On Adult Female Morphology Of Anopheles (Nyssorhynchus) albimanus (Diptera: Culicidae). Invertebrate Reproduction Development 1997;32:85-8.

64. Hribar L. Costal Wing Spot Variation Within And Among Progeny Of Single Female Anopheles nuneztovari (Diptera: Culicidae). 1995. 
65. Hribar L. Geographic Variation Of Male Genitalia Of Anopheles nuneztovari Gabaldon. Mosquito Systematic. 1994;26:132-44.

66. Sallum MAM, Foster PG, Dos Santos CLS, Flores DC, Motoki MT, Bergo ES. Resurrection Of Two Species From Synonymy Of Anopheles (Nyssorhynchus) strodei Root, And Characterization Of A Distinct Morphological Form From The Strodei Complex (Diptera: Culicidae). Journal Of Medical Entomology. 2010;47(4):504-26.

67. Marrelli MT, Sallum MAM, Marinotti O. The Second Internal Transcribed Spacer Of Nuclear Ribosomal DNA As A Tool For Latin American Anopheline Taxonomy: A Critical Review. Memórias Do Instituto Oswaldo Cruz. 2006;101:81732.

68. Bourke BP, Foster PG, Bergo ES, Calado DC, Sallum MAM. Phylogenetic Relationships Among Species Of Anopheles (Nyssorhynchus) (Diptera, Culicidae) Based On Nuclear And Mitochondrial Gene Sequences. Acta Tropica 2010;114(2):88-96.

69. Bourke BP, Oliveira TP, Suesdek L, Bergo ES, Sallum MAM. A Multi-Locus Approach To Barcoding In The Anopheles strodei Subgroup (Diptera: Culicidae). Parasites \& Vectors. 2013;6.

70. Greni SE. A Multi-Gene Analysis And Proposed Distribution Of Species Of The Strodei Subgroup Of Anopheles (Nyssorhynchus) (Diptera: Culicidae). Universidade De São Paulo, Faculdade De Saúde Pública. 2016.

71. Sant'Ana DC, Sallum MAM. Anopheles (Nyssorhynchus) Striatus, A New Species Of The Strodei Subgroup (Diptera, Culicidae). Revista Brasileira De Entomologia. 2017;61(2):136-45.

72. Oliveira-Ferreira J, Lourenco-De-Oliveira R, Deane LM, Teva A, DanielRibeiro CT. Natural Malaria Infections In Anophelines In Rondonia State, Brazilian Amazon. The American Journal Of Tropical Medicine And Hygiene. 1990;43(1):6-10.

73. DEANE LM. A Cronologia Da Descoberta Dos Transmissores Da Malária Na Amazônia Brasilira. Memórias Do Instituto Oswaldo Cruz. 1989;84:149-56.

74. Duarte A, Pereira DM, De Paula MB, Fernandes A, Urbinatti PR, Ribeiro AF, Et Al. Natural Infection In Anopheline Species And Its Implications For Autochthonous Malaria In The Atlantic Forest In Brazil. Parasites \& Vectors. 2013;6.

75. WP T, B D-T. Malaria Vectors In The Brazilian Amazon: Anopheles Of The Subgenus Nyssorhynchus. Revista Do Instituto De Medicina Tropical De São Paulo. 2000;42:87-94.

76. Unti O. Anofelinos Do Vale Do Paraíba. Nota III. Biologia Do Anopheles (Nyssorhynchus) Strodei Root, 1926 Com A Descrição De Uma Variedade Nova: 
Anopheles (Nyssorhynchus) Strodei ramosi Var. Anais Paulista de Medicina e Cirurgia. 1940;40:489-505.

77. Unti O. Anofelinos Do Vale Do Rio Paraíba, Anopheles (Nyssorhynchus) Strodei Root, 1926, Com A Descrição De Três Variedades Novas. 1941;33:3-18.

78. Ruiz-Lopez F, Wilkerson RC, Ponsonby DJ, Herrera M, Sallum MAM, Velez ID, Et Al. Systematics Of The Oswaldoi Complex (Anopheles, Nyssorhynchus) In South America. Parasites \& Vectors. 2013;6.

79. Garros C, Dujardin J-P. Genetic And Phenetic Approaches To Anopheles Systematics, Anopheles Mosquitoes - New Insights Into Malaria Vectors. 2013.

80. Fritz GN, Engman S, Rodriguez R, Wilkerson RC. Identification Of Four Vectors Of Human Plasmodium spp. By Multiplex PCR: Anopheles rangeli, An. strodei, An. triannulatus, And An. trinkae (Diptera : Culicidae : Nyssorhynchus). Journal Of Medical Entomology. 2004;41(6):1111-5.

81. Brown DD, Wensink PC, Jordan E. A Comparison Of The Ribosomal DNA's Of Xenopus laevis And Xenopus mulleri: The Evolution Of Tandem Genes. Journal Of Molecular Biology. 1972;63:57-73.

82. Wesson DM, Porter $\mathrm{CH}$, Collins $\mathrm{FH}$, . Sequence And Secondary Structure Comparisons Of ITS rDNA In Mosquitoes (Diptera: Culicidae). Molecular, Phylogenetic And Evolution. 1992;1:253-69.

83. Rich SM, Rosenthal BM, Telford SR, Spielman A, Hartl DL, Ayala FJ. Heterogeneity Of The Internal Transcribed Spacer (ITS-2) Region Within Individual Deer Ticks. Insect Molecular Biology. 1997;6:123-9.

84. Onyabe DY, Conn JE. Intragenomic Heterogeneity Of A Ribosomal DNA Spacer (ITS2) Varies Regionally In The Neotropical Malaria Vector Anopheles nuneztovari (Diptera: Culicidae). Insect Molecular Biology. 1999;8:435-42.

85. Ritchie A, Blackwell A, Malloch G, Fenton B. Heterogeneity Of ITS1 Sequences In The Biting Midge Culicoides impunctatus (Goetghebuer) Suggests A Population In Argyll, Scotland, May Be Genetically Distinct. Genome 3: 546-558. 2004.

86. Xu J-NN, Qu F-Y. Ribosomal DNA Difference Between Species A And D Of The Anopheles Dirus Complex Of Mosquitoes From China. Medical And Veterinary Entomology. 1997 (11):134-8.

87. NW B, Ellis JT, Cooper RD, Saul A. Discrimination Of All Members Of The Anopheles Punctulatus Complex By Polimerase Chain Reaction Restriction Fragment Lenght Polymorphism Analysis. Insect Molecular Biology. 1999;53:478-81

88. Paskewitz SM, Collins FH. Use Of The Polymerase Chain-Reaction To Identify Mosquito Species Of The Anopheles gambiae Complex. Medical And Veterinary Entomology. 1990;4(4):367-73. 
89. Walton C, Handley JM, Kuvangkadilok C, Collins FH, Harbach RE, Baimai V, Et Al. Identification Of Five Species Of The Anopheles dirus Complex From Thailand, Using Allele-Specific Polymerase Chain Reaction. Medical And Veterinary Entomology. 1999 Feb;13(1):24-32.

90. Torres EP, Foley DH, Saul A. Ribosomal DNA Sequence Markers Differentiate Two Species Of The Anopheles maculatus (Diptera:Culicidae) Complex In The Philippines. Journal Of Medical Entomology. 2000;37(6):933-7.

91. Wilkerson RC, Reinert JF, Cong L. Ribosomal DNA ITS2 Sequences Differentiate Six Species In The Anopheles crucians Complex (Diptera : Culicidae). Journal Of Medical Entomology. 2004;41(3):392-401.

92. Alam MT, Das MK, Dev V, Ansari MA, Sharma YD. Identification Of Two Cryptic Species In The Anopheles (Cellia) annularis Complex Using Ribosomal DNA PCR-RFLP. Parasitology Research. 2007;100(5):943-8.

93. Vogler AP, Desalle R. Evolution And Phylogenetic Information Content Of The ITS-1 Region In The Tiger Beetle Cicindela dorsalis. Molecular Biology And Evolution. 1994;11:393-405.

94. Miller BR, Crabtree MB, Savage HM. Phylogeny Of Fourteen Culex Mosquito Species, Including The Culex pipiens Complex, Inferred From The Internal Transcribed Spacers Of Ribosomal DNA. Insect Molecular Biology. 1996;5:93-107.

95. Gentile G, Della Torre A, Maegga B, Powell JR, Caccone A. Genetic Differentiation In The African Malaria Vector, Anopheles gambiae s.s., And The Problem Of Taxonomic Status. Genetics. 2002;161:1561-78.

96. Quiñones M, Harbach R, Calle D, Ruiz F, Erazo H, Linton Y. Variante Morfológica De Hembras De Anopheles benarrochi (Diptera: Culicidae) En Putumayo, Colombia. Biomédica. 2001;21:351-9.

97. Vidal PO, Peruzin MC, Suesdek L. Wing Diagnostic Characters For Culex quinquefasciatus And Culex nigripalpus (Diptera, Culicidae). Revista Brasileira De Entomologia. 2011;55(1):134-7.

98. Lorenz C, Patane JSL, Suesdek L. Morphogenetic Characterisation, Date Of Divergence, And Evolutionary Relationships Of Malaria Vectors Anopheles cruzii And Anopheles homunculus. Infection Genetics And Evolution. 2015;35:144-52.

99. Jaramillo N, Dujardin JP, Calle-Londono D, Fonseca-Gonzalez I. Geometric Morphometrics For The Taxonomy Of 11 Species Of Anopheles (Nyssorhynchus) Mosquitoes. Medical And Veterinary Entomology. 2015;29(1):26-36.

100. Calle D, Quinones M, Erazo H, Jaramillo N. Differentiation By Geometric Morphometrics Among 11 Anopheles (Nyssorhynchus) In Colombia. Biomedica. 2008;28:371-85. 
101. Bookstein FL. Foundations Of Morphometrics. Annual Review Of Ecology And Systematics. 1982;13:451-70.

102. Monteiro L, Reis S. Princípios De Morfometria Geométrica. 1999.

103. Richtsmeier JT, Deleon VB, Lele SR. The Promise Of Geometric Morphometrics. Yearbook Of Physical Anthropology. 2002;45:63-91.

104. Rohlf FJ. Morphometric Tools For Landmark Data - Geometry And Biology Bookstein, FL. Journal Of Classification. 1993;10(1):133-6.

105. Lorenz C, Almeida F, Almeida-Lopes F, Louise C, Pereira SN, Petersen V, et al. Geometric Morphometrics In Mosquitoes: What Has Been Measured? Infection, Genetics And Evolution. 2017;54:205-15.

106. Lorenz C, Suesdek L. Short Report: Evaluation Of Chemical Preparation On Insect Wing Shape For Geometric Morphometrics. American Journal Of Tropical Medicine And Hygiene. 2013;89(5):928-31.

107. Klingenberg CP. Evolution And Development Of Shape: Integrating Quantitative Approaches. Nature Reviews Genetics. 2010;11(9):623-35.

108. Bitner-Mathé BC, Klaczko LB. Heritability, Phenotypic And Genetic Correlations Of Size And Shape Of Drosophila Mediopunctata Wings. Heredity. 1999;83:688-96.

109. Jirakanjanakit N, Leemingsawat S, Thongrungkiat S, Apiwathnasorn C, Singhaniyom S, Bellec C, et al. Influence Of Larval Density Or Food Variation On The Geometry Of The Wing Of Aedes (Stegomyia) aegypti. Tropical Medicine \& International Health. 2007;12(11):1354-60.

110. Morales-Vargas RE, Ya-Umphan P, Phumala-Morales N, Komalamisra N, Dujardin JP. Climate Associated Size And Shape Changes In Aedes aegypti (Diptera: Culicidae) Populations From Thailand. Infection Genetics And Evolution. 2010;10(4):580-5.

111. Aytekin S, Aytekin AM, Alten B. Effect Of Different Larval Rearing Temperatures On The Productivity (Ro) And Morphology Of The Malaria Vector Anopheles Superpictus grassi (Diptera: Culicidae) Using Geometric Morphometrics. Journal Of Vector Ecology. 2009;34(1):32-42.

112. Gómez GF, Márquez EJ, Gutiérrez LA, Conn JE, Correa MM. Geometric Morphometric Analysis Of Colombian Anopheles albimanus (Diptera: Culicidae) Reveals Significant Effect Of Environmental Factors On Wing Traits And Presence Of A Metapopulation. Acta Tropica 2014;135:75-85.

113. Morales Vargas R, Phumala-Morales N, Tsunoda T, Apiwathnasorn C, Dujardin J. The Phenetic Structure Of Aedes albopictus. Infection, Genetics And Evolution 2013;13(242-251). 
114. Gunz P, Mitteroecker P. Semilandmarks: A Method For Quantifying Curves And Surfaces. Hystrix-Italian Journal Of Mammalogy. 2013;24(1):103-9.

115. Sheets H, Covino K, Panasiewicz J, Morris S. Comparison Of Geometric Morphometric Outline Methods In The Discrimination Of Age-Related Differences In Feather Shape. Frontiers In Zoology. 2006;3.

116. Bookstein FL. Morphometric Tools For Landmark Data. Geometry And Biology Cambridge: Cambridge University Press; 1997;455.

117. Rohlf FJ. Relative Warp Analysis And Example Of Its Application To Mosquito Wing. Madrid: Museo Nacional De Ciencias Naturales. 1993.

118. Devicari M, Lopes AR, Suesdek L. Wing Sexual Dimorphism In Aedes scapularis (Diptera: Culicidae). Biota Neotropica. 2011;11(2):165-9.

119. Lorenz C, Marques TC, Sallum MAM, Suesdek L. Altitudinal Population Structure And Microevolution Of The Malaria Vector Anopheles cruzii (Diptera: Culicidae). Parasites \& Vectors. 2014;7.

120. Virginio F, Vidal PO, Suesdek L. Wing Sexual Dimorphism Of Pathogen-Vector Culicids. Parasites \& Vectors. 2015;8.

121. Christe RD, Wilke ABB, Vidal PO, Marrelli MT. Wing Sexual Dimorphism In Aedes fluviatilis (Diptera: Culicidae). Infection Genetics And Evolution. 2016;45:4346.

122. De Morais SA, Moratore C, Suesdek L, Marrelli MT. Genetic-Morphometric Variation In Culex quinquefasciatus From Brazil And La Plata, Argentina. Memórias Do Instituto Oswaldo Cruz. 2010;105(5):672-6.

123. K.R. Galbo SRT. Fluctuating Asymmetry In The Wings Of Culex Quinquefasciatus (Say) (Diptera: Culicidae) From Selected Barangays In Iligan City, Philippines. AACL Bioflux. 2014;7:357-64.

124. Demari-Silva B, Suesdek L, Sallum MAM, Marrelli MT. Wing Geometry Of Culex Coronator (Diptera: Culicidae) From South And Southeast Brazil. Parasites \& Vectors. 2014;7.

125. Louise C, Vidal PO, Suesdek L. Microevolution Of Aedes Aegypti. Plos One. $2015 ; 10(9)$.

126. Petersen V, Devicari M, Suesdek L. High Morphological And Genetic Variabilities Of Ochlerotatus scapularis, A Potential Vector Of Filarias And Arboviruses. Parasites \& Vectors. 2015;8.

127. Lorenz C, Marques TC, Sallum MAM, Suesdek L. Morphometrical Diagnosis Of The Malaria Vectors Anopheles Cruzii, An. homunculus And An. bellator. Parasites \& Vectors. 2012;5. 
128. Wilke ABB, Christe RD, Multini LC, Vidal PO, Wilk-Da-Silva R, De Carvalho GC, Et Al. Morphometric Wing Characters As A Tool For Mosquito Identification. Plos One. 2016;11(8).

129. Kendall DG. The Diffusion Of Shape. Advances In Applied Of Probability. $1977 ; 9(428-230)$.

130. Rohlf FJ. Shape Statistics: Procrustes Superimpositions And Tangent Spaces. Journal Of Classification. 1999;16(2):197-223.

131. Slice DE, Bookstein FL, Marcus LF, Rohlf FJ. Appendix I: Glossary For Geometric Morphometric. In Marcus LF, Corti M, Loy A, GJP. Naylor And Slice DE. Eds. Advances In Morphometrics Plenum Press, New York And London. 1996:53151.

132. Rohlf FJ. Morphometrics. Annual Reviews Of Ecology And Systematics. 1990;21:299-316.

133. Dujardin JP. Morphometrics Applied To Medical Entomology. Infection Genetics And Evolution. 2008;8(6):875-90.

134. Adams DC, Rohlf FJ, Slice DE. Geometric Morphometrics: Ten Years Of Progress Following The 'Revolution'. Italian Journal of Zoology. 2004;71(1):5-16.

135. Klingenberg CP, Mcintyre GS. Geometric Morphometrics Of Developmental Instability: Analyzing Patterns Of Fluctuating Asymmetry With Procrustes Methods. Evolution. 1998;52:1363-75.

136. Klingenberg CP, Barluenga M, Meyer A. Shape Analysis Of Symmetric Structures: Quantifying Variation Among Individuals And Asymmetry. Evolution. 2002;56:1909-20.

137. Gidaszewski NA, Baylac M, Klingenberg CP. Evolution Of Sexual Dimorphism Of Wing Shape In The Drosophila melanogaster Subgroup. BMC Evolutionary Biology. 2009;9.

138. Fairbairn D, Blanckenhorn W, Székely T. Sex, Size And Gender Roles: Evolutionary Studies Of Sexual Size Dimorphism. 2007.

139. Benitez HA, Bravi R, Parra LE, Sanzana MJ, Sepulveda-Zuniga E. Allometric And Non-Allometric Patterns In Sexual Dimorphism Discrimination Of Wing Shape In Ophion Intricatus: Might Two Male Morphotypes Coexist? Journal Of Insect Science. 2013;13.

140. Darwin C. The Descent Of Man, And Selection In Relation To Sex. 2th Ed. London: John Murray, Albermarle Street; 1874.

141. Fairbairn DJ. Allometry For Sexual Size Dimorphism: Pattern And Process In The Coevolution Of Body Size In Males And Females. Annual Review Of Ecology And Systematics. 1997;28:659-87. 
142. Meyer-Rochow VB, Reid WA. Male And Female Eyes Of The Antarctic Midge Belgica-Antarctica (Diptera, Chironomidae) - A Scanning Electron-Microscope Study. Applied Entomology And Zoology. 1994;29(3):439-42.

143. Adler PH, Adler CRL. Mating-Behavior And The Evolutionary Significance Of Mate Guarding In 3 Species Of Crane Flies (Diptera, Tipulidae). Journal Of Insect Behavior. 1991;4(5):619-32.

144. Eberhard WG. Physical Restraint Or Stimulation? The Function(S) Of The Modified Front Legs Of Male Archisepsis diversiformis (Diptera, Sepsidae). Journal Of Insect Behavior. 2002;15(6):831-50.

145. Wilkinson G, Dodson G. Function And Evolution Of Antlers And Eye Stalks In Flies. Cambridge, UK: Cambridge University Press. 1997.

146. Forattini OP. Culicidologia Médica: EDUSP. 2002;860.

147. Alexander R, Brown Jr W. Mating Behavior And The Origin Of Insect Wings. Ann Arbor, Michigan: University Of Michigan Museum Of Zoology. 1963.

148. Shevtsova E, Hansson C, Janzen DH, Kjaerandsen J. Stable Structural Color Patterns Displayed On Transparent Insect Wings. Proceedings Of The National Academy Of Sciences Of The United States Of America. 2011;108(2):668-73.

149. Cator LJ, Arthur BJ, Harrington LC, Hoy RR. Harmonic Convergence In The Love Songs Of The Dengue Vector Mosquito. Science. 2009;323(5917):1077-9.

150. Speranca MA, Capurro ML. Perspectives In The Control Of Infectious Diseases By Transgenic Mosquitoes In The Post-Genomic Era - A Review. Memorias Do Instituto Oswaldo Cruz. 2007;102(4):425-33.

151. Scali C, Catteruccia F, Li Q, Crisanti A. Identification Of Sex-Specific Transcripts Of The Anopheles gambiae Double Sex Gene. Journal of Experimental Biology. 2005;208:3701-9.

152. Wilkerson RC, Linton YM, Fonseca DM, Schultz TR, Price DC, Strickman DA. Making Mosquito Taxonomy Useful: A Stable Classification Of Tribe Aedini That Balances Utility With Current Knowledge Of Evolutionary Relationships. Plos One. $2015 ; 10(7)$.

153. Reinert J, Harbach R, Kitching I. Phylogeny And Classification Of Tribe Aedini (Diptera: Culicidae). Zoological Journal Of The Linnean Society. 2009;157:700-94.

154. Saez AG, Lozano E. Body Doubles. Nature. 2005;433(111).

155. Bickford D, Lohman DJ, Sodhi NS, Ng PKL, Meier R, Winker K, Et Al. Cryptic Species As A Window On Diversity And Conservation. Trends In Ecology And Evolution. 2006;22. 
156. Mayr E. Animal Species And Evolution. The Belknap Press Of Harvard University Press Cambridge, Massachusetts. 1966.

157. Mayr E. The Bearing Of The New Systematics On Genetical Problems. The Nature Of Species. Advances In Genetics. 1948;[205-37].

158. Houle D, Mezey J, Galpern P, Carter A. Automated Measurement Of Drosophila Wings. BMC Evolutionary Biology. 2003;3.

159. Baylac M, Garnery L, Tharavy D, Pedraza-Acosta J, Rortais A, Arnold G. Apiclass, An Automatic Wing Morphometric Expert System For Honeybee Identification. 2008.

160. Sonnenschein A, Vanderzee D, Pitchers WR, Chari S, Dworkin I. An Image Database Of Drosophila melanogaster Wings For Phenomic And Biometric Analysis. Gigascience. 2015;4.

161. Dujardin J-P. Morphometrics In Medical Entomology - Collection Of Landmark For Identification And Characterization. 2012.

162. Gibas C. Desenvolvendo Bioinformática: Elsevier Editora Ltda; 2002.

163. Stephens ZD, Lee SY, Faghri F, Campbell RH, Zhai C, Efron MJ, Et Al. Big Data: Astronomical Or Genomical? Plos Biology. 2015;13(7).

164. Caterino MS, Cho S, Sperling FAH. The Current State Of Insect Molecular Systematics: A Thriving Tower Of Babel. Annual Review Of Entomology. 1-54.

165. Drăghici S, Sellamuthua S, Khatria P. Babel's Tower Revisited: A Universal Resource For Crossreferencing Across Annotation Databases. Bioinformatics. $2006 ; 22(23): 2934-9$.

166. Elmasri R, Navathe SB. Fundamentals Of Database Systems. 2011. 6th.

167. Date CJ. An Introduction To Database Systems. 4 Ed. 1986.

168. Seltzer M. Beyond Relational Databases. 2008;51.

169. Codd EF. A Relational Model Of Data For Large Shared Data Banks. Communications Of The Acm. 1970;13(6):377-\&.

170. IBM. Icones Do Progresso: Banco De Dados.

171. Chen PP-S. The Entity-Relationship Model: Toward A Unified View Of Data: Library Of The Massachusetts Institute Of Technology; 1977.

172. Date CJ. An Introduction To Database Systems. 8 Ed: Pearson Education, Inc.; 2004. 
173. Everest, G. Basic Data Structure Models Explained With A Common Example. Austin, TX: IEEE Computer Society Publications Office; 1976.

174. Celko J. Joe Celko's SQL Programming Style: Morgan Kaufmann - Elsevier; 2005.

175. Evans E. Domain-Driven Design: Tackling Complexity In The Heart Of Software: Addison Wesley; 2003.

176. Harbach RE. Mosquito Taxonomic Inventory. 2013.

177. Wiley EO, Liebermann BS. Phylogenetic Systematics. 2 Ed. 2011;432.

178. Vences M, Guayasamin JM, Miralles A, De la Riva I. To Name Or Not To Name: Criteria To Promote Economy Of Change In Linnaean Classification Schemes. Zootaxa. 2013;3636:201-44.

179. Rohlf FJ. The Tps Series Of Software. Hystrix-Italian Journal Of Mammalogy. 2015;26(1):9-12.

180. Klingenberg CP. Morphoj: An Integrated Software Package For Geometric Morphometrics. Molecular Ecology Resources. 2011;11(2):353-7.

181. Dujardin, JP. COO, MOG And COV For Windows. Institut De Recherches Pourle Développement. 2010.

182. Dujardin JP, Kaba D, Henry AB. The Exchangeability Of Shape. 2010.

183. Zavortink TJ. Mosquito Studies (Diptera: Culicidae) XXIX. A Review Of The Subgenus Kerteszia Of Anopheles. Contributions of the American Entomological Institute. 1973;9:1-54.

184. Arnell JH. A Review Of The Scapularis Group Of Aedes (Ochlerotatus) . Contributions of the American Entomological Institute. 1976;13.

185. Phylip FJ. Phylogeny Inference Package: University Of Washington; 2005.

186. Consoli RAGB, Lourenço-de-Oliveira R. Principais Mosquitos De Importância Sanitária No Brasil. 1994:225.

187. Benson DA, Cavanaugh M, Clark K, Karsch-Mizrachi I, Lipman DJ, Ostell J, et al. Genbank. Nucleic Acids Research. 2013;41(D1):D36-D42.

188. Jowett T. Preparation Of Nucleic Acids. In: Roberts, D.B. (Ed.), Drosophila A Practical Approach. Roberts DB Press, Oxford. 1986.

189. Sambrook J, Fritsch EF, Maniatis T. Molecular Cloning: A Laboratory Manual. Plainview, NY: Cold Spring Harbor Laboratory Press. 1989;2. 
190. Hall TA. Bioedit: A User-Friendly Biological Sequence Alignment Editor And Analysis Program For Windows 95/98/NT. Nucleic Acids Symposium. 1999;41:95-8.

191. Edgar RC. MUSCLE: Multiple Sequence Alignment With High Accuracy And High Throughput. Nucleic Acids Research. 2004 Mar;32(5):1792-7.

192. Kumar S, Stecher G, Tamura K. MEGA7: Molecular Evolutionary Genetics Analysis Version 7.0 For Bigger Datasets.: Molecular Biology Evolution; 2016.

193. Richards J. Naming Conventions Used In XBRL Taxonomies. 2012.

194. Gaffigan T, Pecor J. Collecting, Rearing, Mounting And Shipping Mosquitoes. 1997.

195. Foley D, Rueda P, Wilkerson R. Vectormap. 2011.

196. Everest, G. Basic Data Structure Models Explained With A Common Example. Austin, TX: IEEE Computer Society Publications Office; 1976.

197. Piatetsky-Shapiro G. Discovery, Analysis, And Presentation Of Strong Rules Knowledge Discovery In Databases. 1991:229-47.

198. Savasere A, Omiecinski E, Navathe S. An Efficient Algorithm For Mining Association Rules In Large Databases. In Proceedings Of The 21st International Conference On Very Large Data Bases. 1995:432-44.

199. Adriaans P, Zantinge D. Data Mining. 1996.

200. Parsaye K, Chignell M. Intelligent Database Tools And Applications: HyperinFormation Access, Data Quality, Visualization, Automatic Discovery. 1999.

201. Fayyad U, Piatetsky-Shapiro G, Smyth Ap. From Data Mining Toknowledge Discovery Indatabases. Al Magazine. 1996;17(3).

202. Dworkin I GG. Epidermal Growth Factor Receptor And Transforming Growth Factor-B Signaling Contributes To Variation For Wing Shape In Drosophila Melanogaster. G3 (Bethesda). 2006;173:1417-31.

203. Klingenberg CP, Zaklan SD. Morphological Integration Between Developmental Compartments In The Drosophila Wing. Evolution. 2000 Aug;54(4):1273-85.

204. Gilchrist AS, Azevedo RBR, Partridge L, O'Higgins P. Adaptation And Constraint In The Evolution Of Drosophila melanogaster Wing Shape. Evolution \& Development. 2000 Mar-Apr;2(2):114-24.

205. Klingenberg CP, Debat V, Roff DA. Quantitative Genetics Of Shape In Cricket Wings: Developmental Integration In A Functional Structure. Evolution. 2010 Oct;64(10):2935-51. 
206. Simmons LW. Correlates Of Male Quality In The Field Cricket, Gryllus Campestris L: Age, Size, And Symmetry Determine Pairing Success In Field Populations. Behavioral Ecology. 1995 Win;6(4):376-81.

207. Chen YP, Why A, Batista G, Mafra-Neto A, Keogh E. Flying Insect Classification With Inexpensive Sensors. Journal Of Insect Behavior. 2014 Sep;27(5):657-77.

208. Bomphrey RJ, Nakata T, Phillips N, Walker SM. Aerodynamic Forces Generated By Wings And The Mechanisms That Produce Them: Trailing-Edge Vortices, Leading-Edge Vortices And Rotational Drag. Nature. 2017.

209. Caprio MA, Huang JX, Faver MK, A M. Characterization Of Male And Female Wing-Beat Frequencies In The Anopheles Quadrimaculatus Complex In Mississippi. Journal Of American Mosquito Control Association. 2001;17:186-9.

210. Robertson SP, Caprio MA, Faver MK. Heritability Of Wing-Beat Frequency In Anopheles Quadrimaculatus. Journal Of The American Mosquito Control Association. 2002 Dec;18(4):316-20.

211. Reeve JP, Fairbairn DJ. Change In Sexual Size Dimorphism As A Correlated Response To Selection On Fecundity. Heredity. 1999;83:697-706.

212. Abbott JK, Bedhomme S, Chippindale AK. Sexual Conflict In Wing Size And Shape In Drosophila Melanogaster. Journal Of Evolutionary Biology. 2010;23(9):1989-97.

213. Moller AP, Zamora-Munoz C. Antennal Asymmetry And Sexual Selection In A Cerambycid Beetle. Animal Behaviour. 1997;54:1509-15.

214. Cepeda-Pizarro J, Vásquez H, Veas H, G C. Relaciones Entre Tamaño Corporal Y Biomasa En Adultos De Tenebrionidae (Coleoptera) De La Estepa Costera Del Margen Meridional Del Desierto Chileno. Revista Chilena de História Natural. 1996;69:67-76.

215. Allen CE, Zwaan BJ, Brakefield PM. Evolution Of Sexual Dimorphism In The Lepidoptera. Annual Review Of Entomology, Vol 56. 2011;56:445-64.

216. Mcalpine D. Observations On Sexual Behavior In Some Australian Platystomatidae (Diptera: Schizophora). Records Of The Australian Museum. 1973;29:1-10.

217. Sivinski J. Ornaments In The Diptera. Florida Entomologist. 1997;80(2):14264.

218. Koekemoer LL, Hargreaves $\mathrm{K}$, Hunt $\mathrm{RH}$, Coetzee M. Identification Of Anopheles Parensis (Diptera : Culicidae) Using Ribosomal DNA Internal Transcribed Spacer (ITS2) Sequence Variation. African Entomology. 2002;10(2):235-9. 
219. Kengne P, Antonio-Nkondjio C, Awono-Ambene HP, Simard F, Awolola TS, Fontenille D. Molecular Differentiation Of Three Closely Related Members Of The Mosquito Species Complex, Anopheles Moucheti, By Mitochondrial And Ribosomal DNA Polymorphism. Medical And Veterinary Entomology. 2007;21(2):177-82.

220. Proft J, Maier WA, Kampen H. Identification Of Six Sibling Species Of The Anopheles Maculipennis Complex (Diptera:Culicidae) By A Polymerase Chain Reaction Assay. Parasitology Research. 1999;85(10):837-43.

221. Kampen H, Sternberg A, Proft J, Bastian S, Schaffner F, Maier WA, Et Al. Polymerase Chain Reaction-Based Differentiation Of The Mosquito Sibling Species Anopheles Claviger S.S. And Anopheles Petragnani (Diptera: Culicidae). American Journal Of Tropical Medicine And Hygiene. 2003;69(2):195-9.

222. Kampen H. The ITS2 Ribosomal DNA Of Anopheles Beklemishevi And Further Remarks On The Phylogenetic Relationships Within The Anopheles maculipennis Group Of Species (Diptera : Culicidae). Parasitology Research. 2005;97(2):118-28.

223. Kampen H. Integration Of Anopheles Beklemishevi (Diptera : Culicidae) In A PCR Assay Diagnostic For Palaearctic Anopheles maculipennis Sibling Species. Parasitology Research. 2005;97(2):113-7.

224. Kengne $\mathrm{P}$, Awono-Ambene $\mathrm{P}$, Nkondjio CA, Simard F, Fontenille D. Molecular Identification Of The Anopheles Nili Group Of African Malaria Vectors. Medical And Veterinary Entomology. 2003;17(1):67-74.

225. Phuc HK, Ball AJ, Son L, Hanh NV, Tu ND, Lien NG, Et Al. Multiplex PCR Assay For Malaria Vector Anopheles minimus And Four Related Species In The Myzomyia Series From Southeast Asia. Medical And Veterinary Entomology. 2003;17(4):423-8.

226. Singh OP, Chandra D, Nanda N, Raghavendra K, Sunil S, Sharma SK, Et Al. Differentiation Of Members Of The Anopheles Fluviatilis Species Complex By An Allele-Specific Polymerase Chain Reaction Based On 28S Ribosomal DNA Sequences. American Journal Of Tropical Medicine And Hygiene. 2004;70(1):27-32.

227. Kengne P, Trung HD, Baimai V, Coosemans M, Manguin S. A Multiplex PCRBased Method Derived From Random Amplified Polymorphic DNA (RAPD) Markers For The Identification Of Species Of The Anopheles minimus Group In Southeast Asia. Insect Molecular Biology. 2001;10(5):427-35.

228. Brelsfoard CL, Fritz GN, Rodriguez R. Sequence Analysis Of The Rdna Internal Transcribed Spacer 2 And Polymerase Chain Reaction Identification Of Anopheles fluminensis (Diptera:Culicidae:Anopheles) In Bolivia. Journal Of Medical Entomology. 2006;43(3):460-6.

229. Henry-Halldin CN, Reimer L, Thomsen E, Koimbu G, Zimmerman A, Keven JB, Et Al. High Throughput Multiplex Assay For Species Identification Of Papua New Guinea Malaria Vectors Members Of The Anopheles punctulatus (Diptera Culicidae) 
Species Group. American Journal Of Tropical Medicine And Hygiene. 2011;84(1):166-73.

230. Thanaphum S, Green CA, Baimai V, Gass RF, JB G. Genetic Linkage Relationships Of Eight Enzyme/Electromorph Loci In Anopheles minimus. Genetica. 1990;82:63-72.

231. Wang Z, Su XM, Wen J, Jiang LY, Qiao GX. Widespread Infection And Diverse Infection Patterns Of Wolbachia In Chinese Aphids. Insect Science. 2014 Jun;21(3):313-25.

232. Fairley TL, Kilpatrick CW, Conn JE. Intragenomic Heterogeneity Of Internal Transcribed Spacer Rdna In Neotropical Malaria Vector Anopheles aquasalis (Diptera : Culicidae). Journal Of Medical Entomology. 2005 Sep;42(5):795-800.

233. Li C, Wilkerson RC. Intragenomic Rdna ITS2 Variation In The Neotropical Anopheles (Nyssorhynchus) albitarsis Complex (Diptera : Culicidae). Journal Of Heredity. 2007 Jan-Feb;98(1):51-9.

234. Baena-López L, Baonza A, García-Bellido A. The Orientation Of Cell Divisions Determines The Shape Of Drosophila Organs. Current Biology. 2005;15(18).

235. Demari-Silva B, Multini LC, Suesdek L, Oliveira TMP, Mureb Sallum MA, Marrelli MT. Wing Morphometry And Genetic Variability Between Culex coronator And Culex usquatus (Diptera: Culicidae), Two Sibling Species Of The Coronator Group. Journal Of Medical Entomology. 2017 Jul;54(4):901-8.

236. Rubio-Palis N. Anopheles (Nyssorhynchus) De Venezuela. Taxonomía, Bionomía, Ecología E Importancia Médica. 2000.

237. Vicente JL, Sousa CA, Alten B, Caglar SS, Falcuta E, Latorre JM, Et Al. Genetic And Phenotypic Variation Of The Malaria Vector Anopheles atroparvus In Southern Europe. Malaria Journal. 2011 Jan;10.

238. Gómez GF, Jaramillo L, Correa MM. Wing Geometric Morphometrics And Molecular Assessment Of Members In The Albitarsis Complex From Colombia. Molecular Ecology Resources. 2013;13:1082-92.

239. Gómez GF, Márquez EJ, Gutiérrez LA, Conn JE, Correa MM. Geometric Morphometric Analysis Of Colombian Anopheles albimanus (Diptera: Culicidae) Reveals Significant Effect Of Environmental Factors On Wing Traits And Presence Of A Metapopulation. Acta Tropica 2014;135:75-85.

240. Zelditch ML, Iderski DLS, H. D. Sheets, Fink. WL. Geometric Morphometrics For Biologists: A Primer. 2014;432.

241. Agarwala R, Barrett T, Beck J, Benson DA, Bollin C, Bolton E, Et Al. Database Resources Of The National Center For Biotechnology Information. Nucleic Acids Research. 2015;43(D1):D6-D17. 
242. Belle E, Grant L, Page W. The Isolation Of St. Louis Encephalitis Virus From Culex Nigripalpus Mosquitoes In Jamaica. American Journal Of Tropical Medicine And Hygiene. 1964;13:452-4.

243. Chamberlain R, Sudia W, Coleman P, Beadle L. Vector Studies In The St. Louis Encephalitis Epidemic, Tampa Bay Area, Florida, 1962. American Journal Of Tropical Medicine And Hygiene. 1964;13:456-61.

244. Dow R, Coleman P, Meadows K, Work T. Isolation Of St. Louis Encephalitis Viruses From Mosquitoes In The Tampa Bay Area Of Florida During The Epidemic Of 1962. American Journal Of Tropical Medicine And Hygiene 1964;13:462-8.

245. Mackay A, Kramer W, Meece J, Brumfield R, Foil L. Host Feeding Patterns Of Culex Mosquitoes (Diptera: Culicidae) In East Baton Rouge Parish, Louisiana. Journal Of Medical Entomology. 2010;47(2):238-48.

246. Unlu I, Kramer W, Roy A, Foil L. Detection Of West Nile Virus RNA In Mosquitoes And Identification Of Mosquito Blood Meals Collected At Alligator Farms In Louisiana. Journal Of Medical Entomology. 2010;47(4):625-33.

247. Guedes D, Paiva M, Donato M, Barbosa P, Krokovsky L, Rocha S, Et Al. Zika Virus Replication In The Mosquito Culex quinquefasciatus In Brazil. Emerging Microbes \& Infection; 2017.

248. Chouin-Carneiro T, Vega-Rua A, Vazeille M, Yebakima A, Girod R, Goindin D, Et Al. Differential Susceptibilities Of Aedes aegypti And Aedes albopictus From The Americas To Zika Virus. Plos Neglected Tropical Diseases. 2016;10(3).

249. Costa-Da-Silva AL, loshino RS, De Araujo HRC, Kojin BB, Zanotto PMD, Oliveira DBL, Et Al. Laboratory Strains Of Aedes aegypti Are Competent To Brazilian Zika Virus. Plos One. 2017;12(2).

250. Costa-Da-Silva AL, loshino RS, Petersen V, Lima AF, Cunha MDP, Wiley MR, Et Al. First Report Of Naturally Infected Aedes aegypti With Chikungunya Virus Genotype ECSA In The Americas. Plos Neglected Tropical Diseases. 2017;11(6).

251. Pauvolid-Correa A, Kenney JL, Couto-Lima D, Campos ZMS, Schatzmayr HG, Nogueira RMR, Et Al. Ilheus Virus Isolation In The Pantanal, West-Central Brazil. Plos Neglected Tropical Diseases. 2013;7(7).

252. SPENCE L, ANDERSON CR, AITKEN TH, DOWNS WG. Melao Virus, A New Agent Isolated From Trinidadian Mosquitoes. American Journal Of Tropical Medicine And Hygiene. 1962;11:687-90.

253. Lopes OD, Sacchetta LD, Francy DB, Jakob WL, Calisher CH. Emergence Of A New Arbovirus Disease In Brazil. 3. Isolation Of Rocio Virus From Psorophoraferox (Humboldt, 1819). American Journal Of Epidemiology. 1981;113(2):122-5.

254. Shannon Rc, Whitman L, Franca M. Yellow Fever Virus In Jungle Mosquitoes. Science. 1938;88:101-10. 
255. Forattini OP. Entomologia Médica. Universidade De São Paulo: Faculdade De Saúde Pública; 1965.

256. Sudia WD. Arthropod Vectors Of Venezuelan Equine Encephalitis. Washington, DC.: Pan American Healt Organization.1972.

257. Aitken THG. Habits Of Some Mosquito Hosts Of VEE Virus From Northeastern South America, In Cluding Trinidad. Venezuelan Encephalitis. 1972:254-6.

258. Ramirez CCL, Dessen EMB. Cytogenetic Analysis Of A Natural-Population Of Anopheles cruzii. Revista Brasileira De Genetica. 1994;17(1):41-6.

259. Schlick-Steiner B, Steiner F, Seifert B, Stauffer C, Christian E, Crozier R. Integrative Taxonomy: A Multisource Approach To Exploring Biodiversity. Annual Review of Entomology. 2010;55:421-38.

260. Mukherjee S, Tamayo P, Rogers S, Rifkin R, Engle A, Campbell C, Et Al. Estimating Dataset Size Requirements For Classifying DNA Microarray Data. Journal Of Computational Biology. 2003;10(2):119-42.

261. Dobbin KK, Zhao Y, Simon RM. How Large A Training Set Is Needed To Develop A Classifier For Microarray Data? Clinical Cancer Research. 2008;14(1):108-14.

262. Tam VH, Kabbara S, Yeh RF, Leary RH. Impact Of Sample Size On The Performance Of Multiple-Model Pharmacokinetic Simulations. Antimicrobial Agents And Chemotherapy. 2006 Nov;50(11):3950-2.

263. Kim SY. Effects Of Sample Size On Robustness And Prediction Accuracy Of A Prognostic Gene Signature. BMC Bioinformatics. 2009;10.

264. Kalayeh HM, Landgrebe DA. Predicting the required number of training samples. 1983;5(6):664-7.

265. Nigam K, Mccallum AK, Thrun S, Mitchell T. Text Classification From Labeled And Unlabeled Documents Using EM. Machine Learning. 2000;39(2-3):103-34.

266. Lorenz C. Emprego de técnicas morfométricas, espectrometria MALDI-TOF e sequenciamento genético para classificação e filogenia de Culicidae (Diptera). Tese de Doutorado - Parasitologia. São Paulo - Instituto de Ciências Biomédicas Universidade de São Paulo. 2017. 